ISSN: 0213-2060

DOI: https://doi.org/10.14201/shhme2018361107133

\title{
LA PREBOSTAD DE LAS VILLAS VASCAS: ORIGEN Y TRANSFORMACIONES (SIGLOS XII-XVI) ${ }^{1}$
}

\author{
The Provost Position or Prebostad in Basque Towns: \\ The Beginning and Development $\left(12^{\text {th }}-16^{\text {th }}\right.$ Centuries)
}

\author{
Imanol VITORES CASADO \\ Depto. de Historia Medieval, Moderna y de América. Facultad de Letras. Universidad del País Vasco. Paseo de la \\ Universidad, 5. E-01006 VITORIA-GASTEIZ. C. e.: imanol.vitores@ehu.eus
}

Recibido: 2016-11-27

Revisado: 2017-10-17

Aceptado: 2018-05-18

RESUMEN: La organización de los sistemas de gobierno de las villas septentrionales vascas tuvo en la prebostad una de sus principales notas distintivas. Asumiendo funciones tributarias y de orden ejecutivo, el acceso al cargo permitió un rápido encumbramiento de las élites locales. Fuentes de renta, influencia en la toma de acuerdos y elecciones, o amplias facultades para el control del tránsito de personas y mercancías son algunas de las virtudes agrupadas en una figura pronto reclamada por granados representantes de bandos y parcialidades. Analizar la casuística que originó la implantación y desarrollo de una magistratura cuyos perfiles han sido poco o desigualmente trabajados por la historiografía precedente es la finalidad principal que persigue este trabajo.

Palabras clave: Preboste; Concejo; Élites; Ciudad; Justicia; Economía; Comercio; Hacienda.

ABSTRACT: The provost position or «prebostad» was one of the emblems of the political organizations of the southern Basque towns. This position was closely linked to both

1 Publicación que se inscribe en el marco del proyecto Poder, sociedad y fiscalidad al norte de la Corona de Castilla en el tránsito del Medievo a la Modernidad. Ref. HAR2014-52469-C3-3-P. Red «Arca Comunis». 
the tax and executive functions; therefore, the access to this post brought a fast promotion of local elites. The provost position had a series of prerogatives such as the supervision of the incomes, the influence on agreements and on elections, or the control over people and goods. That is why the post was quickly claimed by local oligarchies. In this way, the aim of this paper is to analyze the casuistry that caused the implantation and development of this post, something that has been little or unequally worked by the historiography.

Keywords: Provost position; Council; Elite; City; Justice; Economy; Trade; Treasury.

SUMARIO: 0 Introducción. 1 Origen, difusión y titularidad de la prebostad en las villas vascas. 2 Nombramiento, atribuciones y competencias anexas a la prebostad. $3 \mathrm{La}$ prebostad como renta de naturaleza aduanera. $4 \mathrm{~A}$ modo de balance o conclusión. 5 Apéndice de tablas. 6 Referencias bibliográficas.

\section{INTRODUCCIÓN}

Al igual que en los cabildos eclesiásticos ${ }^{2}$, algunas monarquías y señoríos medievales se sirvieron de los prebostes para lo referente a la administración territorial y de justicia en el marco de villas y ciudades. Si monarcas franceses y navarros fueron quienes fundamentalmente dotaron a estos oficiales -junto a bailes y senescales- de una mayor presencia o relevancia en sus dominios, en la Corona de Castilla sus homónimos detentaron igualmente destacadas prerrogativas pese a que su representatividad y ámbito de influencia distaran de ser tan relevantes. Generalizada su presencia como especificidad institucional de las villas vascas, los prebostes acumularon importantes competencias en el seno de los concejos, haciendo de esta magistratura un codiciado instrumento de poder $^{3}$. A lo largo de las siguientes páginas ahondaremos en el contexto que vio nacer la

2 Primera Partida, Título VI, ley III. Seguimos la edición de Madrid: Boletín Oficial del Estado, 2004, 3 vols.

3 Sin ánimo alguno de exhaustividad y siguiendo un cierto orden cronológico, cabría presentar aquí un somero balance en torno al enfoque, metodología y resultados de las principales publicaciones que han tratado en uno u otro momento sobre la figura de la prebostad a fines de la Edad Media. Partiendo del marco estrictamente local, en la línea de los estudios dedicados al análisis de los concejos o corporaciones urbanas, las primeras aportaciones al respecto centraban su atención en la descripción de competencias anexas al cargo, haciendo énfasis en la condición de sus titulares. Entre otros, cabría señalar los trabajos de GARCía DE CORTÁZAR, José Ángel. Vizcaya en el siglo XV. Aspectos económicos y sociales. Bilbao: Ediciones de la Caja de Ahorros Vizcaína, 1966, pp. 195-203; OreLla Unzué, José Luis. «Régimen municipal en Guipúzcoa en los siglos XIII y XV». Lurralde: Investigación y espacio, 1979, vol. 2, pp. 103-267; García de Cortázar, José Ángel y otros. Bizcaya en la Edad Media. San Sebastián: Haranburu Editor, 1985, vol. IV, pp. 39-46; Achón Insausti, José Ángel. 'A voz de Concejo'. Linaje y corporación urbana en la constitución de la Provincia de Gipuzkoa. San Sebastián: Diputación Foral de Gipuzkoa, 1995, pp. 174 y 184, o Tena García, M. ${ }^{a}$ Soledad. La sociedad urbana en la Guipuizcoa costera medieval: San Sebastián, Rentería y Fuenterrabia (1200-1500). San Sebastián: Instituto Doctor Camino, 1997, pp. 313, 322-326, 382-430. Posteriores investigaciones, sin proporcionar destacables novedades documentales a este respecto, insistieron igualmente en el instrumento de poder que su- 
prebostad -o prebostazgo- para enumerar sus ámbitos o esferas de actuación, reparar en la calidad de sus titulares y concretar así su trascendencia en los debidos términos.

\section{ORIGEN, DIFUSIÓN Y TITULARIDAD DE LA PREBOSTAD EN LAS VILLAS VASCAS}

La aparición de la figura de los prebostes nos retrotrae necesariamente al proceso de fundación de las villas en el marco de la Cornisa Cantábrica. Desde finales del siglo XII, mediante la concesión de los denominados "fueros de francos», algunas de las nacientes pueblas vieron paulatinamente incorporado este cargo en la nómina de gobernantes llamados a formar el concejo. De forma separada o independiente, monarcas navarros y castellanos, así como los propios señores de Vizcaya, difundieron y adaptaron estos ordenamientos en sus dominios, imprimiendo no obstante algunas especificidades institucionales sobre las fundaciones de ámbito vasco. Atendiendo a la marcada ubicación u orientación litoral de la región, así como a su condición fronteriza, los nuevos enclaves instituidos fundamentalmente en los territorios guipuzcoano y vizcaíno tendieron a erigirse como «villas de prebostad». Esta especificidad, difundida y salvaguardada a la postre por la monarquía castellana, afianzó la singularidad administrativa de dichas localidades, especialmente en los ámbitos de su organización territorial y hacendística.

La primera referencia al cargo en las villas vascas la hallamos en el fuero de San Sebastián otorgado por el monarca navarro Sancho VI el Sabio (1180). El ordenamiento contemplaba la prerrogativa de los pobladores para nombrar anualmente preboste y alcalde, reproduciendo a este respecto los esquemas organizativos empleados por la monarquía navarra en sus núcleos urbanos ${ }^{4}$. En el ámbito de las finanzas públicas, el texto

puso la prebostad, siendo una magistratura deseada o codiciada por determinados linajes del entorno próximo o inmediato a las villas. Algunas referencias en este sentido pueden consultarse en DACOstA, Arsenio. Los linajes de Bizkaia en la Baja Edad Media: poder, parentesco y conflicto. Bilbao: Universidad del País Vasco, 2003, pp. 109-112, 272-274. En relación también al señorío de Vizcaya, un primer intento por trazar las líneas fundamentales de la institución (origen, prerrogativas, esferas de actuación) a través del análisis exhaustivo de las fuentes conservadas, tanto en archivos locales como generales, fue acometido por Vitores Casado, Imanol. Poder, sociedad y fiscalidad en el Señorio de Vizcaya durante la Baja Edad Media. Vitoria-Gasteiz: Universidad del País Vasco, 2014 (Tesis doctoral inédita), pp. 353-404. Desde una aproximación local o regional, posteriores estudios trajeron de nuevo a colación la problemática de la prebostad y su continuidad o equiparación de atribuciones con desiguales resultados. Destacan aquí las reflexiones y aportaciones de trabajos como los de IrIJOA CorTÉs, Iago. «Gobierno urbano en San Sebastián a fines de la Edad Media: crisis de linaje, conflictos y reestructuración política». Boletín de Estudios Históricos sobre San Sebastián, 2016, vol. 49, pp. 19-37; Estudio de la vida urbana guipuzcoana: los valles del Oria y Urumea en la Baja Edad Media. Vitoria-Gasteiz: Universidad del País Vasco, 2015 (Tesis doctoral inédita), vol. III, pp. 858-879.

4 «Et ego dono per fuero populatoribus Sancti Sebastiani ut in unoquoque anno, ad capud anni, mutent propositum et alcaldum». Martín Duque, Ángel J. «El fuero de San Sebastián. Tradición manuscrita y edición crítica». En Congreso El Fuero de San Sebastián y su época. San Sebastián: Sociedad de Estudios Vascos, 1982, p. 25. En los dominios navarros, salvo contadas excepciones, prebostes, justicias y almirantes eran los oficiales encargados de la ejecución de la justicia en villas y ciudades, cuya existencia data, al menos, de mediados del siglo Xi. Ramírez Vaquero, Eloísa. «Hacienda y poder real 
recogía igualmente la relación y tasas de diversos impuestos regios de carácter aduanero, referidos en este caso a las embarcaciones que arribaran a la localidad. Frente a la exención de los avecindados, la monarquía navarra se sirve de antiguos peajes como la «lezda» y el «portazgo», adaptando no obstante su tasación respecto a la operante en Pamplona ${ }^{5}$.

Tras la conquista y adhesión de los territorios de Álava y Guipúzcoa bajo Alfonso VIII de Castilla (c 1200), la utilidad y validez del fuero de San Sebastián quedaba constatada mediante su implantación en las nuevas pueblas del litoral guipuzcoano. Es de suponer que el monarca renovara parte del articulado navarro para acomodarlo a la realidad administrativa del reino, especialmente en lo relativo a la implantación de la moneda castellana como referencia para el pago de impuestos y penas ${ }^{6}$. En este sentido, con motivo de la concesión de la carta puebla de Fuenterrabía (1203), aforada al forum de Sancto Sebastiano, la donación del puerto de Astuniaga a la localidad venía acompañada del pago de una renta anual tasada en maravedís 7 . Las pretensiones por reivindicar los derechos sobre el territorio gascón ocupan en estos momentos la atención del monarca. Junto a su esposa Leonor, hija de Enrique II y Leonor de Aquitania, Alfonso VIII convocaba en la villa del Urumea (1204) a significativas personalidades del entorno meridional del condado para iniciar la inminente ofensiva ${ }^{8}$. La defensa de Bayona, liderada por su preboste P. Sarresin, contaría

en Navarra en la Baja Edad Media. Un esquema teórico». Príncipe de Viana, 1999, vol. 60, n. ${ }^{\circ} 216$, p. 107. En este sentido, el articulado otorgado a San Sebastián venía a servirse del cuerpo de oficiales retratado en el fuero de Estella (1164): «Quicumque voluerit populare in Stella e esse vicinus Stelle, hoc faciat cum consensu e voluntate prepositi e alcaldi e iuratorum Stelle». LaCARRA DE Miguel, José María. "Fuero de Estella». Anuario de Historia del Derecho Español, 1927, vol. 4, p. 434.

5 «Similiter dono et concedo quod populatores de Sancto Sebastiano qui per mare ad Sanctum Sebastianum arribauerint uel per terram, et ad predictam villam cum sua mercatoria venerint, non dent lezdam nec ibi nec in tota mea terra. Hoc solummodo retineo: quod si aliquis de populatoribus ad Bayonam trossellos uel aliquam mercatoriam comparauerint, et per Sanctum Sebastianum transierint ut in alio loco vendant predictam mercaturiam, donet lezdam [...]. Similiter volo et dono per fuero quod proprie naues de Sancto Sebastiano sint franqs et libere et ingenue, quod non dent portague nec lezdam. Sed naues stranee dent lezdam: de unaquaque navi $\mathrm{X}$ solidos mee monete; et de unoquoque trossello quod de naue extractum fuerit, XII denarios de arribaje insuper suam lezdam, set minus terciam partem quam daret per fuero in Pampilona». MARTín DuQue, «El fuero de San Sebastián», p. 15. Los ordenamientos de Estella y Jaca incluían asimismo oportunas referencias sobre el pago de la «lezda». Lacarra de Miguel, «Fuero de Estella», p. 422. Líbano Zumalacárregi, Ángeles. "Consideraciones lingüísticas sobre algunos tributos medievales navarro-aragoneses y riojanos». Principe de Viana, 1979, vol. 40 , n. ${ }^{\circ} 154-155$, p. 73.

6 Con fecha en 1203, un 17 de julio, parece existir constancia documental de la conformación de los fueros de San Sebastián por Alfonso VIII, según Pamplona, Germán de. «Sancho el Fuerte, iniciador de las relaciones amistosas con la ciudad de Bayona». Príncipe de Viana, 1962, vol. 23, n. ${ }^{\circ}$ 88-89, p. 496. La datación la retrotrae al 16 de agosto de 1202 GonZÁLeZ, Julio. El reino de Castilla en la época de Alfonso VIII. Madrid: Escuela de Estudios Medievales, 1960, vol. III, p. 273.

7 «E concedo uobis illu portum de Astuniaga quod sit semper uester, cum tali tam pacto quod uno quoque anno detis pro illo portu quinquaginta marbotinos». LARRAÑAGa Zulueta, Miguel y TApia Rubio, Izaskun. Colección documental del Archivo Municipal de Hondarribia. Tomo I (1186-1479). San Sebastián: Eusko Ikaskuntza, 1993, doc. 3.

8 Los vizcondes de Béarn, Tartas, Orthez, el conde de Armagnac o los obispos de Bayona y Bazas asistieron a una reunión donde se procedió a la concesión de 15 campesinos o "paysans» a la iglesia y 
con fuerzas de apoyo navarras resultado del acuerdo previamente firmado entre Sancho el Fuerte y Enrique II de Inglaterra' ${ }^{9}$. Siguiendo la crónica castellana, cercada la villa y una vez corrió toda la tierra en derredor, esta prometía su homenaje si el rey accedía a levantar el sitio para tomar Burdeos. El relato llega a afirmar la rendición y pleitesía de la çibdat de Burdel [...] e de toda la Gascoña, dejando a expensas de una futura contienda con el monarca inglés el destino de la ciudad ante la urgencia de la ofensiva almohade ${ }^{10}$.

Prosiguiendo en su política fundacional, las villas de Guetaria, Motricu (1209) y San Vicente de la Barquera (1210) adoptaban el fuero de San Sebastián, incorporando y asumiendo así la figura del preboste ${ }^{11}$. En las villas cántabras, en época del propio Alfonso VIII comprobamos por otro lado la operatividad de rentas aduaneras como portazgos y diezmos en los puertos, siendo parte de su rédito cedido a centros eclesiásticos burgaleses $^{12}$. Entretanto, Juan I de Inglaterra otorgaba privilegi de le comunie [...] aus ciptadans de Baione (1215). Asumiendo el modelo u ordenamiento de La Rochelle, el monarca reservaba no obstante para la Corona saubas a nos en totes causes, nostra prebostat, e nostres custumes, e nostres franqueses que en medisse la nostra ciptad de Baione deuem auer cum auem en le nostre biele de la Rochele [... $]^{13}$. De forma coetánea, en lo que respecta al menos a la implantación de fueros y ordenamientos, o a la incipiente aparición de impuestos y tasas aduaneras, los procesos de nacimiento y desarrollo de los enclaves litorales cantábricogascones parecieron seguir dinámicas similares.

A lo largo de la decimotercera centuria, en el territorio guipuzcoano prosiguen las iniciativas para la erección de nuevas villas, fortaleciendo fundamentalmente los asentamientos de interior ubicados en las cuencas de los ríos Oria y Deva. Frente a la actuación de Fernando III en el litoral -concesiones o confirmaciones del fuero de San Sebastián a las localidades de Zarauz ${ }^{14}$ y Oyarzun (1237)-, a lo largo de apenas una década Alfonso X

obispo de Dax. Acta donde el monarca arroga y firma bajo las acepciones de «Dominus Vasconiae» o «Ego Alphonsus regnans in Castilla et Toledo et in Vasconia». Monlezun, Jean-Justin. Histoire de la Gascogne depuis les temps les plus reculés jusqu’à nos jours. Auch: J. A. Portes, Imprimeur, 1850, vol. II, pp. 248-249.

9 El texto lo publica Pamplona, «Sancho el Fuerte», p. 500. Otras referencias complementarias a este respecto en BALASQue, Jules. Études historiques sur la ville de Bayonne. Bayonne: Lasserre, 1862, vol. I, pp. 320-328.

${ }_{10}$ Crónica de Alfonso VIII, Capítulo II, Títulos 9-10. Edición digital Paris, SEMH-Sorbonne CLEA (EA 4083) (Les Livres d'e-Spania «Sources», 1), 2010, http://e-spanialivres.revues.org/187

11 La premeditación o el interés de la Corona por reforzar las pueblas en la línea litoral del Cantábrico puede inferirse del propio relato cronístico: «E entonçe pobló Castro de Ordiales, e Gitarria, e Laredo e Motrico, e Santander, e Sant Viçente de la Barquera, todo esto costera de la mar». Ibídem, Título 6. Un estudio de conjunto sobre las cartas puebla de las villas cántabras, junto con su edición, lo llevó a cabo en su momento Martínez Díez, Gonzalo. «Fueros locales en el territorio de la provincia de Santander». Anuario de Historia del Derecho Español, 1976, vol. 46, pp. 527-608.

12 Ibidem, pp. 559-560, 567.

13 Balasque, Études historiques, vol. I, pp. 452-453. Si no antes, al menos desde finales del siglo XII los vizcondes del Labourd cobran igualmente diezmos y otros peajes sobre el puerto de la localidad para cederlos coyunturalmente a instituciones eclesiásticas. Ibidem, p. 396.

14 La carta emitida al concejo de Zaráuz contemplaba el cobro anual de dos sueldos por hogar y la entrega de una parte de toda ballena capturada. Gorosábel, Pablo de. Diccionario histórico- 


\section{2}

hacía lo propio en otras cinco pueblas, aforadas en este caso al ordenamiento de Vitoria de $1181^{15}$. En este contexto, la monarquía comienza a reservarse la atribución para el nombramiento del preboste, limitando o invalidando así los términos contemplados a este respecto en el fuero de San Sebastián en beneficio de los avecindados. En remuneración a los servicios prestados en las campañas marítimas de la reconquista, vasallos como los donostiarras Mans obtienen en merced la prebostad para detentarla como cargo vitalicio, vinculándolo además al linaje en forma de juro de heredad ${ }^{16}$. Miembros y descendientes de dicha parentela copan cargos en el concejo y cabildo de San Sebastián -llegando a alcanzar la mitra de Bayona ${ }^{17}$-, destacan como dueńos y maestres de embarcaciones para participar igualmente en los arrendamientos de rentas regias vinculadas al tráfico de mercancías como los diezmos ${ }^{18}$.

geográfico-descriptivo de los pueblos, valles, partidos, alcaldías y uniones de Guipuizcoa con un apéndice de las cartas puebla y otros documentos importantes. (1. a ed. Tolosa, 1862). Bilbao: La Gran Enciclopedia Vasca, 1972, p. 733.

15 En la travesía del Oria, Tolosa, Ordicia y Segura recibían su carta puebla en 1256, mientras que, de forma escalonada, Mondragón (1260) y Vergara (1268) harían lo propio pocos ańos después en la cuenca del Deva. Puntos intermedios o de escala todos ellos que conectarían Vitoria con los puertos guipuzcoanos.

16 El privilegio otorgado por Sancho IV a Guillem Per de Mans (1285) insiste en el papel jugado por este en el cerco de Jerez, "por el serviçio que nos fizo en esta flota que nos mandamos armar quando Abenyuçat tenia çercada la villa», haciendo referencia a la concesión previa de Alfonso $\mathrm{X}$ a favor de Ordincho de Mans, abuelo del beneficiario. La prebostad de San Sebastián incluía el derecho anual a la "primera media ballena de Guetaria». Banús y AguirRe, José Luis. «Prebostes de San Sebastián. Los Mans y Engómez». Boletín de Estudios Históricos sobre San Sebastián, 1971, vol. 5 , pp. 17-18. En época de Fernando III, Ordincho de Mans habría participado igualmente en la toma de Sevilla fletando un navío propio que pone al servicio del almirante Ramón Bonifaz. Un exhaustivo estudio sobre la trayectoria e influencia de este linaje en los entramados de poder local lo llevó a cabo Tena García, M. a Soledad. «Los Mans-Engómez: el linaje dirigente de la villa de San Sebastián durante la Edad Media». Hispania, 1993, vol. 185, pp. 987-1008. Recientemente, un estudio en torno a la problemática de la transmisión del cargo entre los miembros de su parentela lo aborda IrIJOA CoRTÉs, Iago. «Donostiako probestutzaren oinordetza XIII eta XIV. mendeetan: Ordincho Mansekoaren eta Martin Gomez-en garaietako korapiloak askatuz». Boletín de Estudios Históricos sobre San Sebastián, 2016, vol. 49, pp. 623-631.

17 Ibidem, pp. 993-995; BalasQue, Études historiques, vol. II, pp. 567-568.

18 Según consta en las cuentas de Sancho IV, Per de Nordench fue arrendador de la renta de los diezmos entre el 28 de enero de 1293 y el 1 de octubre de 1294. A tenor de lo contemplado en los registros, en estos momentos el partido o distrito fiscal de dicho arrendamiento, separado del de las cuatro villas cántabras, comprendía los puertos de «San Sebastian et Fuenterabia et Guetaria et de los otros puertos de Guipuzcoa». El recabdo presentado en Valladolid incluía puntos aduaneros litorales y de interior como los de Oyarzun, Orio, Segura o el puerto de San Adrián. Gaibrois de Ballesteros, Mercedes. Historia del reinado de Sancho IV de Castilla. Madrid: Real Academia de la Historia, 1922, vol. I, (apéndice) pp. XXII-XXIV y XL. El recaudador de los diezmos debió representar a la villa de San Sebastián en la fundación de la Hermandad de la Marina de Castilla con Vitoria en 1296, según Tena García, «Los Mans-Engómez», p. 993. Al respecto del contexto guipuzcoano de dicha renta, una perspectiva general la ofreció en su momento DíEz de SALAZAR, Luis Miguel. El diezmo viejo y seco, o diezmo de la mar de Castilla (siglos XIII-XVI): aportación al estudio de la fiscalidad guipuzcoana. San Sebastián: Caja de Ahorros Municipal de San Sebastián, 1983. 
A fines del siglo xir la figura del preboste hacía su aparición en el colindante señorío de Vizcaya para extenderse en los nacientes núcleos urbanos. La iniciativa señorial encaminada a la fundación de nuevas pueblas estuvo en este caso lejos de corresponderse a la acometida por los monarcas castellanos en la línea litoral del cantábrico. Frente a las iniciales pueblas de Bermeo (c 1214) u Ochandiano (c 1236), aparentemente carentes de adscripción foral alguna, la extensión de los modelos de Vitoria y, fundamentalmente, de Logroño (1095) correspondió a villas nacientes o consolidadas en las postrimerías de la centuria: Lanestosa (1287), Durango (c 1297) y Plencia (1299) ${ }^{19}$. Es precisamente en la carta de refundación concedida por Diego López de Haro $\mathrm{V}$ a esta última localidad donde se hace por vez primera referencia expresa al preboste como autoridad operante en $\mathrm{Bermeo}^{20}$. Como cargo inexistente tanto en el fuero de Logrońo como en las propias cartas puebla otorgadas previamente por los titulares del señorío, cabría reflexionar sobre las posibles causas que motivaron el surgimiento y difusión de la prebostad en las fundaciones vizcaínas.

La inclusión de Bermeo en la hermandad de las villas de la marina de Castilla con Vitoria (1296) debió necesariamente acercar posturas entre esta y las localidades adscritas. Los términos de la asociación, añadamos, bastante alejados de los postulados de la rival y más antigua Societas navium Baionensium (c 1215) ${ }^{21}$, contemplaron disposiciones referentes también a la fiscalidad operante en el reino. Concretamente, a la negativa de la institución a satisfacer la renta de los diezmos y la saca del fierro, que son cosas contra fuero, al tiempo que quedaba decretado el cese de las relaciones con Bayona, Inglaterra y Flandes mientras prosiguiera la guerra entre franceses e ingleses ${ }^{22}$. En este contexto, cabría suponer que la mayor presencia y protección de grupos vizcaínos directa o indirectamente vinculados al sector (concejos, mercaderes, navieros, vasallos) generaran intereses tendentes a la búsqueda de cierta correspondencia en lo relativo a la fiscalidad aduanera exigida en el señorío respecto a la operante en otros territorios. Ciertamente, hasta la consolidación de la prebostad como renta sobre el tráfico de mercancías, los señores de Vizcaya carecieron de gabelas o fórmulas para la obtención de réditos de dicha naturaleza. De forma paralela, la recurrente presencia de los Haro y de las huestes vizcaínas en campañas como las de Sevilla o Jerez, donde localidades del litoral cantábrico prestaron

19 Para una visión de conjunto en torno al proceso fundacional vizcaíno ZABALA, M. ${ }^{\mathrm{a}}$ José. «La creación de las villas en el Señorío de Bizkaia: los fueros y las cartas pueblas». Cuadernos de Sección Historia-Geografia Eusko Ikaskuntza, 1995, vol. 23, pp. 11-29.

20 «E do bos el mi monte de Isoquiza en goarda del mi preboste de este lugar que les guarde, ansi como guarda el preboste de Bermeo el monte de Galdiz». Iturriza y Zabala, Juan Ramón de. Historia general de Vizcaya y epitome de las Encartaciones. 2. ${ }^{a}$ ed. Bilbao: Ediciones de la Librería Arturo, 1983, Escritura núm. 48. Disposición que se repite en la carta puebla de Bilbao de 1300: «Et do el mio monte de Ollargan en guarda del mio prevoste d'este lugar, qu'él guarde, assi como guarda el mio prevoste e Bermeo el monte de Galdiz». Enríquez Fernández, Javier y otros. Colección documental del Archivo Histórico de Bilbao (1300-1473). San Sebastián: Eusko Ikaskuntza, 1999, doc. 1.

21 La edición de su acta constitutiva puede consultarse en BALASQUe, Etudes historiques, vol. II, pp. 439-449.

22 Benavides, Antonio. Memorias de D. Fernando IV de Castilla. Madrid: Imp. de José Rodríguez, 1860, vol. II, n. ${ }^{\circ}$ LVII, p. 81. 


\section{4}

laureados servicios por mar, debió traer consigo el desarrollo de consecuentes iniciativas para la organización de esta forma de guerra en el territorio. En un momento en el que la monarquía castellana impulsa mediante diversas medidas la creación de la armada, los vínculos e influencia detentados en estas fechas por los seńores de Vizcaya sobre la institución del almirantazgo invitarían a plantear la existencia de posibles marcos de actuación o de adaptación en este sentido ${ }^{23}$. Como veremos, los réditos de rentas como la de la prebostad, al igual que buena parte de la fiscalidad ordinaria devengada en los territorios vascos septentrionales, tenderá a vincularse a la contratación de hombres de armas, esto es, empleada en la cesión de «tierras» $\mathrm{y}$ «acostamientos» para el reclutamiento de los denominados vasallos mareantes.

De forma genérica, llegado el siglo xiv la extensión de los distintos modelos forales en la creación de nuevas villas sancionó la incorporación de los prebostes en la nómina de oficiales concejiles, en algunos casos, incluso en aquellas localidades donde dicha figura no constaba de forma expresa en los ordenamientos de origen. En Guipúzcoa, pueblas como las de Rentería (1320), Zumaya (1347), Orio (1370) o Usúrbil (1371), tomando como base y referencia el fuero de San Sebastián, tienden a reproducir su cuerpo de gobierno quedando adscritas a esta como instancia de apelación o alzada en las causas judiciales ${ }^{24}$. El articulado de privilegios como el de Orio constata igualmente el interés de la Corona por impulsar la creación de los concejos como fórmula para controlar o redirigir el tráfico de mercancías y maximizar réditos en puntos aduaneros preexistentes. En este caso, la localidad costera albergaría en exclusividad la carga y descarga de las embarcaciones que aportaran en la desembocadura del río Oria, distribuyendo asimismo la producción de las ferrerías del entorno como almacén prioritario de pesaje y tributación ${ }^{25}$. La elección anual de los cargos del concejo, incluyendo al preboste, es todavía una atribución teóricamente reservada a los parroquianos de la iglesia de San Nicolás:

«Por facer bien y merced a vos los parroquianos de la iglesia de San Nicolas de Orio, que me lo enviastes pedir por merced, e porque es mio servicio y pro y poblamiento de vos los dichos parroquianos, porque seades mejor guardados e amparados vos, e vuestros bienes, e los otros

23 En relación con la presencia militar y a la proximidad de los señores de Vizcaya con los almirantes de Castilla del periodo tratábamos en Vitores Casado, Poder, sociedad y fiscalidad, pp. 625-632. Para una lectura más detallada en torno a las vicisitudes de la armada de Castilla resulta de marcado interés el trabajo de García de CASTRo, Francisco Javier. La marina de Guerra de la Corona de Castilla en la Baja Edad Media. Desde sus origenes hasta el reinado de Enrique IV. Valladolid: Universidad de Valladolid, 2011 (Tesis doctoral inédita), pp. 44-48.

24 A este respecto, la carta puebla de Zumaya establecía «que hayan los que ella poblaren el fuero de San Sebastian, asi como los de San Sebastian han el fuero de Jaca, e según que lo han e son poblados al dicho fuero las villas de San Sebastian, Guetaria y Motrico, y que hayan y pongan alcalde, preboste, jurados y escribanos públicos y fieles y oficiales, según que los han y ponen en San Sebastian, Guertaria y Motrico, y de los juicios y sentencias de los alcaldes del dicho lugar de Villagrana de Zumaya que hayan las alzadas para San Sebastian y de San Sebastian para nuestra corte». Gorosábel, Diccionario histórico, p. 734.

25 Una reciente revisión de conjunto en torno a la producción, compraventa y fiscalidad vinculada al hierro en los territorios vascos puede consultarse en Vitores CaSAdo, Imanol. «Agentes económicos e instituciones públicas en la configuración del mercado del hierro vasco (siglos xIV-XvI): poder, crédito y finanzas». En la España Medieval, 2017, vol. 40, pp. 191-247. 
mercaderes viandantes que van e vienen por la tierra e por la mar en la dicha tierra y comarca y collacion, porque se pueda mejor mantener el peaje del brazo de mar que corre y es cerca de la dicha iglesia e parroquia, tengo por bien [...] que ayades el fuero de la villa de San Sebastian e todas las franquezas, libertades, buenos usos e buenas costumbres que el dicho concejo de la villa de San Sebastian ha de los reyes onde yo vengo e de mi, e que pongades en la dicha villa por cada año alcaldes, prebostes, jurados, escribanos, e otros oficiales cualesquier, según en la dicha villa de San Sebastian los han e suelen poner, e que sea en la dicha villa de Villarreal de San Nicolás de Orio la carga e descarga de los navios que en la dicha canal e brazo de mar de Orio aportaren. E otrosi, que sea y en la dicha villa el peso e renteria del fierro que en las ferrerias de las comarcas se ficiere e labrare, esto por razón que sobre el dicho brazo de mar de Orio non hay otra villa poblada, porque serán mejor guardadas e recabdadas en dicha villa todas las rentas e pechos e derechos que a mí pertenecen en las dichas comarcas e ferrerias para mi servicio [...] ${ }^{26}$.

Localidades interiores de nueva fundación, sucedidas a lo largo de las cuencas de los ríos Deva y Urola, prosiguen con la adopción y difusión del ordenamiento de Vitoria o de sus modelos derivados ${ }^{27}$. Sin constar en su articulado y por lo tanto inexistente en las villas alavesas, la figura del preboste aparece, no obstante, documentada por estas fechas en algunas de las localidades guipuzcoanas regidas por dicha modalidad foral. Si bien desconocemos las causas o procedimientos que sancionaron la incorporación del cargo, lo cierto es que en villas como Mondragón, Vergara o Cestona sus titulares ejercieron competencias en idénticos o similares términos a los de las homónimas localidades de ámbito litoral aforadas al fuero de San Sebastián. Al igual que ocurrió en pueblas como Placencia (1343), Éibar y Elgóibar (1346) que asumen en este caso la carta puebla de Logrońo como texto de referencia ${ }^{28}$.

En la vecina Vizcaya, donde de forma genérica es este último modelo el difundido en las villas fundadas a lo largo de la decimocuarta centuria, la prebostad, asumida prácticamente por todos los núcleos urbanos, se rige o atiende a criterios distintos en uno u otro momento. Frente a las iniciales atribuciones otorgadas a los concejos para el nombramiento del cargo entre el vecindario, acompañadas poco tiempo después por coyunturales cesiones de la renta para, como en Bermeo (1334), aliviar los gastos de la erección de su muralla ${ }^{29}$, en adelante, la política de los señores a este respecto comenzará

26 Ibidem, pp. 697-698.

27 Icíar-Deva (1294/1343), Azpeitia (1310), Azcoitia (1324), Elgueta (1345), Urrechu o Cestona (1383) son fundaciones que adoptan el fuero vitoriano de 1181 o los de localidades guipuzcoanas de este derivadas, como Mondragón o la propia Azpeitia.

${ }_{28}$ El cotejo y consulta de buena parte de estos privilegios y referencias pueden acometerse con celeridad en la citada obra de Pablo de Gorosábel. Igualmente, resulta de marcado interés el trabajo de Orella Unzué, José Luis. «La familia del fuero de Logroño en Guipuzkoa hasta la promulgación de la merindad mayor en el Ordenamiento de Alcalá en 1348». En García Turza, Francisco Javier y Martínez Navas, Isabel (coords.). Actas de la reunión cientifica El Fuero de Logroño y su época. Logroño: Ayuntamiento de Logroño, 1996, pp. 323-389. En páginas siguientes trataremos sobre las vicisitudes de la prebostad en los núcleos no adscritos al modelo de San Sebastián, por lo que serán señaladas las indicaciones documentales específicas de cada caso.

29 El mismo año los pescadores de Lequeitio obtenían algunas rebajas sobre la contribución de la prebostad, cuya titularidad y recaudación parece estar bajo control del concejo. Asimismo, a comienzos del siglo xv localidades como Plencia habían obtenido en merced la cesión de dicho cargo y renta. Una exposición más detallada al respecto en Vitores Casado, Poder, sociedad y fiscalidad, pp. 361-362. 


\section{6}

a mostrarse más restrictiva. En la carta puebla de Guerricáiz (1366), don Tello se arrogaba la potestad para, vía merced, escoger entre los vecinos al preboste ${ }^{30}$. Siguiendo la misma tendencia, ańos después, en 1375, el infante don Juan organizaba de forma separada la elección del concejo de Miravalles, de periodicidad anual, frente a los dos escribanos perpetuos y al preboste, ordenando que este lleve sus derechos que pertenecen a la prebostad.

Ante la carencia de menciones expresas al cargo en la legislación general del reino ${ }^{31}$, a partir de la segunda mitad del siglo XIV reales cédulas y textos jurídicos territoriales constatan la consolidación del mismo como magistratura de ámbito urbano, detentando la autoridad ejecutiva de la villa o ciudad en cuestión. Por lo tanto, en las villas de prebostad, dicho oficial asumiría las atribuciones que a este respecto ejercían merinos o adelantados en el marco de la Corona de Castilla ${ }^{32}$. De forma cuasi coetánea, las referencias al preboste entre justicias y dignidades generales de la administración comienzan a documentarse tanto en los textos emanados de la cancillería castellana como en los de su equivalente vizcaína ${ }^{33}$. Ordenamientos como el de la Hermandad de Guipúzcoa (1397) establecerán asimismo de forma precisa tanto la distinción de jurisdicciones respecto a los merinos de la tierra como la asignación reservada al oficial sobre multas y penas: si fuere en la villa que sea para el preboste, e si fuere fuera de la villa, de la cerca fuera, que sea para el merino ${ }^{34}$.

30 EnríQuez Fernández, Javier. Colección documental de los Archivos Municipales de Guerricáiz, Larrabezúa, Miravalles, Ochandiano, Ondárroa y Villaro. San Sebastián: Eusko Ikaskuntza, 1991, doc.1.

31 Tanto en las Partidas como en el Ordenamiento de Alcalá el preboste no consta entre los oficiales regios o concejiles contemplados en ambos compendios. Respecto al último, seguimos la edición de Asso y del Río, Ignacio Jordán de y Manuel y Rodríguez, Miguel de, Madrid, 1847. No obstante, referencias aisladas al cargo aparecen en el cuaderno de las Cortes de Jerez de 1268 en relación con el control de mercancías en los puertos de las villas de San Sebastián y Fuenterrabía. Véase nota 70.

32 Para una visión de conjunto Sánchez-Arcilla Bernal, José. «La administración de justicia en León y Castilla durante los siglos x al xiII». En Riesco Terrero, Ángel (coord.). I Jornadas sobre documentación jurídico-administrativa, económico-financiera y judicial del reino castellano-leonés (siglos X-XIII). Madrid: Universidad Complutense de Madrid, 2002, pp. 13-49.

33 Por citar algunos ejemplos en este sentido, en 1351, en la carta de confirmación emitida por Pedro I al concejo de Vitoria ordenaba amparar el privilegio a «todos los conçeios, alcalles, jurados, jueces, justiçias, merinos, alguasiles, maestres de las ordenes, comendadores, suscomendadores, bayles, prebostes, alcaydes de los castiellos, portadgueros e a todos los otros offiçiales e aportellados de las çibdades e villas e logares de mis regnos». González Mínguez, César. Documentos de Pedro I y Enrique II en el Archivo Municipal de Vitoria. San Sebastián: Eusko Ikaskuntza, 1994, doc. IV. Por su parte, en Vizcaya el infante don Juan hacía lo propio al referirse en 1376 «al prestamero [...], e a todos los conçejos e alcaldes e prebostes e jurados e juezes e justiçias e otros oficiales qualesquier de todas las villas e lugares del mi Sennorio de Vizcaya». Hidalgo de Cisneros, Concepción y otros. Fuentes jurídicas medievales del Señorio de Vizcaya. Cuadernos legales, Capitulos de la Hermandad y Fuero Viejo (1342-1506). San Sebastián: Eusko Ikaskuntza, 1986, p. 50. Para una descripción de la cancillería castellana de la Edad Media: Salazar Acha, Jaime de. «La cancillería real en la Corona de Castilla». En Sarasa Sánchez, Esteban (coord.). Monarquía, crónicas, archivos y cancillerías en los reinos hispano-cristianos. Zaragoza: Institución Fernando el Católico, 2014, pp. 309-324. Cabría igualmente señalar que al menos desde 1405 el señorío contó con una Escribanía de los Privilegios de Vizcaya que trabajaba en Valladolid. CaÑas Gálvez, Francisco de. El itinerario de la Corte de Juan II de Castilla (1418-1454). Madrid: Sílex, 2007, p. 18.

34 Barrena Osoro, Elena. Ordenanzas de la Hermandad de Guipuzcoa (1375-1463). San Sebastián: Eusko Ikaskuntza, 1982, doc. III, artículos 22 y 50. Previamente, el fuero de ferrerías de Irún 
Aunque difícil de precisar, escuetas y en ocasiones dispersas referencias, procedentes en su mayoría de fuentes municipales, permiten intuir una progresiva vinculación o exclusividad de las prebostades en beneficio de escogidos linajes y parentelas. Mediante distintas fórmulas, la promoción de las élites urbanas en el seno de los concejos tuvo en el acceso a este cargo una vía de actuación e influencia a considerar. Al igual que en San Sebastián, en representativas villas vascas -fundamentalmente en las de ámbito litoral- la anualidad contemplada en buena parte de las cartas puebla comienza a dar paso a un tiempo de ejercicio más dilatado y continuado. Ello en un contexto en el que propietarios de casas y dominios solariegos del entorno asientan su posición en los núcleos urbanos para acabar optando igualmente a los órganos del gobierno municipal. En el transcurso del siglo XIV, el análisis de escogidos ejemplos sirven como referentes con los que ilustrar este proceso.

El solar de Ugarte, establecido tiempo atrás en la tierra de Oyarzun, ejerce desde temprano una palpable influencia sobre las nacientes villas del entorno. Siguiendo la crónica de Lope García de Salazar, el tildado solar más antiguo de toda Guipuscoa que del bando de Ganboa sea, coetáneo y rival del labortano Urtubia, muestra una especial inclinación por las prebostades. Desde su torre o palacio, señores de la casa, como Ayoro de Ugarte, destacan en la década de los sesenta al servicio del rey de Castilla; concretamente, en 1364, como escudero que mantiene conpannas en la frontera con Navarra y Gascuña ${ }^{35}$. En noviembre de dicho año, Sancho Sánchez de Ugarte consta ya en los documentos de la villa de Rentería ejerciendo como preboste ${ }^{36}$. El cronista portugalujo situaba el origen del asentamiento del linaje en la localidad en la generación de los nietos del citado Ayoro -o en un antecesor homónimo-. Es el segundón Martín Sánchez de Ugarte, hijo de Petri Sánchez de Ugarte, quien fue a poblar a la villa de la Renteria para ser nombrado igualmente preboste de la misma. Por otro lado, en tiempos de Ayoro la familia accede a la prebostad de la localidad de Orio para cederla a sus descendientes. Pese a las limitaciones del fondo municipal de Rentería, la progresión del linaje tanto en esta como en la tierra de Oyarzun puede inferirse de su presencia en cargos y actividades administrativas. Mientras algunos de sus miembros ejercen como notarios públicos (Rentería, 1384) o son electos como procuradores para la representación del concejo (Oyarzun, 1406), los titulares de la casa de Ugarte constan igualmente en calidad de testigos en actos de primer orden como la división de límites jurisdiccionales acordada en 1409 entre la villa y el colindante señorío de Murgía. El encargado de averiguar y establecer por orden regia los mojones respectivos no es otro que Pedro López de Ugarte, mi vasallo e mi preboste en la Villa Nueva de Oyarzun (Rentería) ${ }^{37}$. La panorámica descrita en las Bienandanzas

Iranzu-Oyarzun incluía a los prebostes entre las autoridades de la provincia de Guipúzcoa encargadas de velar por los privilegios concedidos a los dueños y trabajadores de las industrias.

35 Crespo Rico, Miguel Ángel y otros. Colección documental del Archivo Municipal de Rentería. Tomo I (1237-1470). San Sebastián: Eusko Ikaskuntza, 1991, doc. 11.

36 Ibidem, doc. 9.

37 A este respecto, cabría reparar en la acepción o terminología empleadas en relación con el cargo en una u otra localidad en distintos momentos. Si, a la altura de 1364, el concejo de la tierra 
viene no obstante a incidir en la hegemonía de la parentela sobre ambas demarcaciones, llegando a afirmar: toviendo estos de Ugarte toda la tierra e villa por su mando. A la altura de 1413, la intromisión y pugna por el control de la villa de Rentería con los Gamboa pareció dirimirse por la fuerza sancionando la expulsión final del linaje. El relato cronístico, insistimos, cuida en seńalar la importancia de la prebostad como uno de los instrumentos clave para el dominio del poder en el marco urbano:

«En el año del señor de CDXIII años, ovo mucha guerra en el valle de Yogarço entre los de la villa de La Renteria e los del solar de Ugarte porque Juan de Gamboa echó de la dicha villa a Martin Sanchez de Ugarte e le tomó la prevostad d'ella, que era suya e lo fuera siempre de su linaje. E ovieron fuerte pelea acerca de la dicha villa e fueron desvaratados los Ugarte e morieron alli aquel Martin Sanchez de Ugarte e otros con él. E dende a pocos dias, salieron Martin de Ibarrra, fijo vastardo de Juan Lopez de Gamboa, que estava alli en ayuda del dicho Juan de Gamboa, e otros con él, que avia muerto aquel Martin Sánchez, e seguieronlos los de Ugarte e mataron acerca de la dicha villa al dicho Martín de Ibarra e a dos sus sobrinos e otros. E asi perdieron los de Ugarte el mando de la dicha villa ${ }^{38}$.

Aun con sus propias especificidades, otras localidades costeras guipuzcoanas parecieron seguir dinámicas similares. Como descendiente bastardo de los Gamboa cuenta Lope- Juan López de Gamboa, hijo de Sancho Pérez, fue a casar e poblar en la villa de Çumaya. Su descendiente Lope Fernández fue provoste de aquella villa, del cual sucedieron e suceden buenos escuderos, e fueron provostes e omes buenos d'estado e ay muchos buenos escuderos, fasta Lope de Cumaya que agora es proboste e mayor d'ellos ${ }^{39}$. Sin poder refutar las aseveraciones del cronista, los registros municipales de la localidad constatan, pese a los notables vacíos, una alternancia de la prebostad entre las familias de Arteaga, Iraeta e Iceta desde los años noventa del siglo XIV hasta entrado el XVI ${ }^{40}$. En el mismo sentido, en Deva, uno de los dos linajes gamboínos atreguados al solar de Olaso es el linaje del prevoste de Deva, que son naturales de [Icíar] e fueron e son provostes

de Oyarzun asumía como propia la titularidad del mismo refiriéndose a Juan Ruiz de Olazábal como nuestro preboste, a comienzos del siglo xv la atribución para su nombramiento en la adyacente villa de Rentería parece corresponder al monarca. Ibidem, docs. 8 y 24. En torno a la presencia de los Ugarte en puestos municipales, docs. 21, 27, 30 y 33 .

38 Villacorta Macho, M. ${ }^{a}$ Consuelo (ed.). Bienandanzas e fortunas. Bilbao: Universidad del País Vasco, 2015, Libro XXI, p. 790. El asentamiento de la casa Ugarte en la villa es relatada en el Libro XX, p. 729. Frente a la afirmación del cronista en torno a la propiedad indiscutida del cargo, en 1384 Juan Pérez de Gabiria consta como preboste en Rentería. Pudiera tratarse, con todo, de uno de los lugartenientes nombrados por la casa de Ugarte o una coyuntural cesión. En referencia al año 1364, el fondo municipal permite igualmente documentar a Lope Ibáńez de Durango como «prevoste por nuestro sennor el rey en la villa de Sant Sebastián», en un contexto en el que, teóricamente, es la familia Mans quien detenta la prebostad como juro de heredad. Crespo Rico y otros, Colección documental, docs. 8 y 19. Una probable alianza matrimonial de este último con la heredera de los derechos del linaje parece ser la vía de acceso al cargo en este preciso momento, según IrIjOA CorTés, «Donsotiako probestutzaren», pp. 630-631.

39 Bienandanzas e fortunas, Libro XX, p. 729.

40 Elorza Maiztegi, Javier. Documentación del Archivo Municipal de Zumaia (1256-1520). San Sebastián: Eusko Ikaskuntza, 2009, docs. 15, 18, 28, 33, 35, 53 y 55. 
de aquella villa ${ }^{41}$. Representantes de la familia Irarrazábal constan en este caso copando el cargo de forma continuada, amén de otras alcaldías y magistraturas, si no antes, a partir al menos de $1390^{42}$.

En Vizcaya, los datos concernientes a algunas de las principales localidades vendrían a corroborar dicha tendencia. Un continuado y heredado ejercicio de la prebostad se desprende de casos como el de Bilbao, donde familias como las de Arbolancha (1321-1353) o Iruarecheta (1387-c 1398) se turnan a lo largo del siglo xiv en el desempeño de la prebostad y, de forma más breve, también en algunas de las alcaldías ${ }^{43}$. En referencia a los primeros, el relato de las Bienandanzas, haciendo consciente alusión al cargo, describe la pensada política matrimonial llevada a cabo por el linaje con los Leguizamón, Salcedo u otros miembros de la nobleza castellana ${ }^{44}$. Por su parte, en Bermeo, la prebostad, detentada por el linaje local de los Areilza, pasaría al control de los Arteaga, descendientes de los Avendaño, tras la muerte del fundador del solar, Furtún García, a manos de Pedro I en Villarreal. Su primogénito y heredero, Martín Ruiz, casó con la fija de Martin Garcia de Arilça de Vermeo, e ovo la prebostad de aquella villa con ella ${ }^{45}$. El asentamiento del linaje de Yarza en la villa de Lequeitio, con la erección de la torre que da nombre al mismo, ribera a la mar, se debería al mismo pariente que, siendo el primero que allí pobló, consiguió ocupar el distinguido cargo para que, en adelante, d'éste suçedier[a]n siempre los probostes de aquella villa ${ }^{46}$. Asimismo, descendientes del linaje de Salazar contraen nupcias y se avecindan en Portugalete para vincular en la práctica al mismo la prebostad que ganó en merced Ochoa de Salazar, que casó con doña Teresa de Muñatones, fija eredera del solar e mayorazgo de Muñatones ${ }^{47}$. Siguiendo la crónica, dicha casuística parece reproducirse en villas como Ondárroa, donde descendientes del solar de Arancibia asientan su poder en la localidad mediante la pretensión y el control del cargo; en otras palabras, fueron e son provostes de la villa de Ondarro, e mayores d'ella ${ }^{48}$. Como veremos, llegado el siglo xv, granados representantes de bandos y parcialidades han copado la titularidad y el ejercicio de unas prebostades cuya cesión o nombramiento depende ya de la consiguiente merced por parte de los reyes.

Exceptuando el temprano ejemplo de San Sebastián, el análisis sistemático de los privilegios para el nombramiento del cargo puede acometerse a partir del reinado de Juan II. En este sentido, depósitos municipales y, sobre todo, archivos generales como el de Simancas conservan destacados e ineludibles registros. Centrándonos en el articulado y cláusulas de dichas mercedes, conviene reparar en la tipología de las atribuciones vinculadas a la prebostad, al igual que en la nómina de derechos, gracias y obligaciones enumeradas, con objeto de delimitar en sus debidos términos la potestad de dichos oficiales en el

41 Bienandanzas e fortunas, Libro XX, p. 729.

42 Elorza Maiztegi, Documentación, doc. 16; Herrero Liceaga, Victoriano José y Barrena Osoro, Elena. Archivo Municipal de Deba. I. (1181-1520). San Sebastián: Eusko Ikaskuntza, 2005, docs. $19,43,48,54,56,62,65,68,76$ y 90 .

43 Enríquez Fernández y otros, Colección documental del Archivo, docs. 5, 40, 24, $36,38$.

44 Bienandanzas e fortunas, Libro XXI, pp. 734-736 y 742-744.

45 Ibidem, Libro XXI, pp. 734 y 740.

46 Ibidem, p. 734.

$47 \quad$ Ibidem, p. 757.

48 Ibidem, p. 734. 
ámbito del poder. Pese al carácter eminentemente normativo o protocolario de este tipo documental, necesariamente reiterativo, el análisis comparado de los registros permite en ocasiones identificar algunas especificidades a nivel local o territorial.

A mediados del siglo Xv, la elección del cargo, de carácter inequívocamente vitalicio, corresponde al monarca, quien procede generalmente a confirmar la renuncia y traspaso en vida del titular en beneficio de su primogénito o de algún individuo próximo a su círculo. De forma excepcional, ante la muerte del primero en acto de servicio, hubo casos en los que se sancionó el nombramiento de herederos, familiares o tutores correspondientes. Las vacantes por fallecimiento, previa notificación por parte del concejo, dieron pie igualmente a la concesión de mercedes a favor de nuevos titulares como ocurrió en Mondragón a la altura de $1451^{49}$. El criterio o mérito por el que la Corona decide aprobar la merced se refiere siempre a la consabida fórmula de atender o recompensar la fidelidad de los servicios prestados, si bien conceptos como los de sufçiençia e ydoneydad salen también a colación puntualmente. El recién nombrado preboste, como oficial de ámbito estrictamente urbano, ejercerá sus competencias en el marco jurisdiccional de la localidad objeto, esto es, tanto intramuros como en el alfoz o términos a esta dependientes: es mi merçed que agora e de aqui adelante, para toda vuestra vida, seades mi prevoste de la dicha mi villa de Mondragon e de toda su tierra e juridiçion. En las pueblas de litoral, oportunas referencias en torno a los límites de mar quedan también ocasionalmente apuntadas en los privilegios. En casos como el de Motrico (1495) se insistía a este respecto en las competencias del preboste sobre la dicha villa de Motrico e su juridiçion, e puerto, e concha, e abra, e muelle ${ }^{50}$. De forma genérica, una primera enumeración define las competencias del oficial en materia ejecutiva, tareas o acciones de orden policial sobre las que se derivan consiguientes asignaciones y tasas a modo de retribución o salario ${ }^{51}$. En determinados casos -Ondárroa (1475), Portugalete (1476)- referencias específicas relativas al cobro de impuestos aduaneros como peajes, portazgos y treintazgos son igualmente señaladas. Como veremos, a diferencia de los merinos, la nota distintiva del preboste radicaba en las atribuciones añadidas al cargo en el terreno de la fiscalidad, para cuya recaudación titulares y concejos procedieron a la elaboración de específicos «aranceles de prebostad». Documentos donde son tipificadas las actuaciones y derechos del oficial en ambas esferas, como ejecutores de la justicia y recaudadores de rentas. Por otro lado, las mercedes contemplan también atribuciones para el nombramiento de lugartenientes ${ }^{52}$.

49 En el prolegómeno del privilegio se hacía constar la antigua e indiscutida prerrogativa regia sobre los nombramientos al declarar: «por quanto yo soy informado que en la mi villa de Mondragon [...] non ay prevoste alguno que tenga el dicho ofiçio nin yo he proveydo de él despues que finó la persona que postrimeramente por mí la tuvo; e por quanto a mí pertenesçe la provision del dicho ofiçio de prevostad, segund derecho e antigua costumbre de la dicha villa». Crespo Rico, Miguel Ángel y otros. Colección documental del Archivo Municipal de Mondragón. Tomo III (1451-1470). San Sebastián: Eusko Ikaskuntza, 1996, doc. 127.

50 AGS, RGS, leg. 1495-XI, fol. 10.

51 Entre otras, voces como «prisiones», «carcelajes», «penas», «calońas», «cotos», «homiçidios», «ejecuçiones», «prendas», «premias» o «afincamientos» quedan apuntadas en las mercedes de nombramiento como, de forma menos precisa, "quitaçiones, derechos, salarios e las otras cosas acostumbradas e al dicho ofiçio perteneçientes».

52 En relación con Vizcaya, un documentado trabajo se centró en la figura de los lugartenientes autoría de Romero ANDONegi, Asier. «La figura del teniente de preboste o "prebostao" en las villas marítimas del señorío de Vizcaya». Zainak. Cuadernos de Antropología-Etnografía, 2002, vol. 21, pp. 317-332. 
Dirigidas a los respectivos concejos, pertinentes órdenes para aceptar y respetar el nombramiento son remitidas acto seguido. La convocatoria de justicias y oficiales concejiles con objeto de proceder al consiguiente juramento y toma de posesión, con la solepnidad que en tal caso se requiere, es no obstante un imperativo formal no necesariamente inexcusable. Las mercedes incorporaban potestad para el ejercicio de la magistratura en caso de que la elección fuera negada o no reconocida, subrayando por tanto la subordinación del poder municipal a este respecto ${ }^{53}$. Con todo, contar con el beneplácito del concejo era un necesario aval con el que perpetuar y hacer valer también toda una serie de prerrogativas anexas al cargo que, en cierto modo, consiguen promocionar la condición social del titular en el seno de la comunidad. De forma un tanto sutil o menos precisa, las cartas de nombramiento se refieren a una serie de dones y gratitudes complementarias que exceden el ámbito meramente corporativo o concejil ${ }^{54}$. Aunque difícil de establecer con rotundidad, como veremos, algunos de estos distintivos ańadidos parecieron estar en relación con la exención de impuestos, la influencia en la entrega de beneficios eclesiásticos o la visibilidad en procesiones y celebraciones religiosas. Una de las incompatibilidades consignadas en los privilegios tiene que ver precisamente con la prohibición de que el titular hubiera recibido tonsura u orden menor alguna ${ }^{55}$, al tiempo que en las prebostades cedidas en juro de heredad se incide en la imposibilidad de su venta o traspaso a eclesiásticos y foráneos al reino sin la pertinente licencia regia ${ }^{56}$. Algunas mercedes de nombramiento incluyeron igualmente los derechos de patronato y rentas de determinadas iglesias parroquiales ${ }^{57}$, mientras que en Vizcaya al menos, con carácter general, una tercera parte del diezmo eclesiástico recaudado en la jurisdicción de las villas correspondía a su preboste.

A los beneficiarios se les exigió, no obstante, determinadas contraprestaciones. Particularmente visibles en el caso de las vizcaínas, algunas mercedes traían aparejada la obligación de servir con un número prefijado de lanzas y ballesteros mareantes. Por tanto, la concesión del cargo -como consta de forma expresa en casos como los de Bermeo, Ondárroa, Villaro, Marquina, Ermua o Portugalete- genera o perpetúa vínculos de vasallaje. En calidad de «tierra y acostamiento», es la propia renta de la prebostad, cuya recaudación y gestión corresponde al mismo oficial, la que asume o soporta la retribución

53 En 1452, la respuesta a la negativa (violenta) del concejo de Mondragón al reconocimiento de su convecino Lope García de Arcaraso como preboste se tradujo en el emplazamiento de la corporación ante el Consejo Real. Crespo Rico y otros, Colección documental, doc. 138.

54 Términos como «honras», "graçias», «merçedes», «franquezas», «libertades», "preeminençias» o "ynmunidades» son incluidos en este sentido como acciones o demostraciones a guardar.

55 Prebostad de Mondragón. Crespo Rico y otros. Colección documental, doc. 127.

56 Prebostad de Portugalete. AGS, RGS, leg. 1476-III, fol. 112.

57 En Cestona (1485), la merced concedida a Juan Beltrán de Iraeta tras la muerte de su padre y titular en la armada incluía los derechos sobre los templos de Ayzarnazabal, Oiquina, Ayzarna y Santa Cruz de Cestona. Ayerbe Iribar, M. a Rosa y Elorza Maiztegi, Javier. Archivo Municipal de Zestoa (1338-1520). Sebastián: Eusko Ikaskuntza, 2008, doc. 37. Por su parte, en Villaviciosa de Marquina (1486), Furtún Ibáńez de Marquina recibía agrupados en un único privilegio la prebostad de esta, el cargo de merino y los derechos de patronazgo de Xemein y Mendata junto con sus diezmos. AGS, EMR-TCV, leg. 1, fol. 30. 
de dichos servicios, con la característica de que, frente a la habitual tasación o cómputo del situado, el privilegio sancionaba el disfrute íntegro de esta con su "demasía»" ${ }^{58}$. Si bien es cierto que no en todos los casos se precisan la tipología de las obligaciones militares a cumplimentar, resolviendo este aspecto con una genérica alusión a la esperada continuidad de la fidelidad y méritos previamente mostrados, la calidad de los prebostes parece estar muy vinculada a la guerra marítima y de frontera. A una palpable presencia en los Libros y nóminas de vasallos mareantes de Vizcaya y Guipuizcoa $a^{59}$ se les unen representativos cargos en las armadas, tenencias de fortalezas como la de Fuenterrabía o capitanías de frontera. Por tanto, condición y característica propia de los titulares de la prebostad es también su reseñable posición en los cuadros militares de la Corona.

Frente a los méritos en el ámbito de la guerra, la venalidad del cargo queda también documentada como procedimiento de acceso a la vez que elemento para el fortalecimiento de vínculos de carácter privado. En este sentido, las prebostades de algunas de las localidades principales o más pobladas de la región jugaron dicho papel a lo largo del siglo xv. Por mediación del concejo de San Sebastián, en 1425 Juan II prohibía al preboste Martín Gómez de forma taxativa, bajo pena de revocación, venta o traspaso alguno del cargo fuera de su parentela. Acusado de haber procedido a la cesión -o de pretender hacerlo- en beneficio de persona poderosa o de tregua de fuera de la jurisdiçion de la dicha villa, la corporación municipal comunicaba al monarca su temor ante las muchas enemistades e males e dapnos que ello podía acarrear, que seria ocasion porque la dicha villa se despoblase $e^{60}$. Lejos de la mera pretensión, en época de Enrique IV, Pedro Sánchez de Venesa pareció haber invertido una notoria cuantía para titularse preboste de Fuenterrabía. Tiempo después, ante la concesión a perpetuidad del cargo en beneficio del concejo (1496), su hijo Juan Sánchez alegaba a los reyes llegando a reclamar que el dicho conçejo le satisficiese e pagase todo lo que por el dicho ofiçio [...] su padre avia pagado, con más lo que avia gastado en la corte ${ }^{61}$. En similares términos Pedro de Muncháraz, quien fuera alcaide de los alcázares de Segovia por Enrique IV, aseguraba haber comprado la prebostad de Bilbao, denunciando la desposesión de su ejercicio por Ochoa de Bedia, quien sería emplazado para comparecer al respecto ante el Consejo Real ${ }^{62}$.

58 Prebostad de Portugalete: «e es nuestra merçed que si los dichos derechos del dicho ofiçio de prebostad valen o valieren más agora o en algund tienpo de lo que las dichas dos lanças e tres vallesteros con que asi por ello nos avedes de servir, que la tal demasia sea vuestra». AGS, RGS, leg. 1475-III, fol. 112.

59 Cuadernos específicos donde los Contadores Mayores de la Real Hacienda inscribían y mantenían al día el conjunto de hombres e instituciones que, a cambio de un computado servicio, gozaban de mercedes con recargo a las rentas ordinarias de ambos territorios. Fuera de la prebostad, los mismos titulares del cargo asientan mercedes añadidas en este sentido sobre rentas como los pedidos, ferrerías, alcabalas, diezmos de la mar, o sobre derechos de patronazgo. La sección Escribanía Mayor de RentasTierras y Cartas Vizcainas del Archivo General de Simancas constituye sin duda el fondo fundamental para su análisis.

60 Banús y Aguirre, «Prebostes de San Sebastián», p. 46.

61 AGS, RGS, leg. 1496-XI, fol. 307.

62 AGS, RGS, leg. 1475-I, fol. 63. Entre 1398-c 1484, las fuentes municipales permiten comprobar el ejercicio continuado del cargo por representantes de los Bedia sin constar traspaso o titular ajeno a la familia. La nómina de prebostes en Bilbao es fácilmente rastreable a través de las fuentes 
Cuenta más detallada en torno a las competencias de los prebostes nos la proporcionan los propios aranceles. Remitiendo a un siguiente apartado lo relativo a la fiscalidad, conviene detenernos, siquiera brevemente, en las atribuciones que en materia ejecutiva vienen desarrolladas en dichos registros. Datados en cronologías tardías, localizados en su mayoría bien a través de traslados o en pleitos que aluden a su articulado de forma indirecta, la tasación -o puesta al día- de los derechos debidos a este oficial son resultado aparente de la negociación entre titular y concejo. La participación y sanción de los últimos consta al menos en los documentos relativos a San Sebastián (c 1449), Deva (1481), Bermeo (1518) y Lequeitio (1522). A grandes rasgos, cuestiones relativas a llamamientos, emplazamientos y "rebeldías», embargos y ejecuciones de bienes, o al traslado y custodia de prisioneros por orden de juez son objeto de detallada tasación, precisando incluso tanto el ámbito civil o criminal como la ubicación intra/extramuros de la actuación a desempeñar; generalmente en cuotas cifradas en blancas o en unas pocas decenas de maravedís. Las penas por homicidios y delitos de sangre se computan por el contrario en niveles considerablemente superiores, en doblas de oro o marcos de plata. En el caso concreto de Bermeo, pertinentes instrucciones relativas a la defensa de las competencias del preboste, el derecho al porte de armas o a la posibilidad de solicitar oportunos refuerzos vendrían a cumplimentar el articulado.

Debido tanto a las desavenencias habidas en la renovación de las tasas, así como a la decidida acción de los concejos por hacerse con el control del poder ejecutivo en el marco de las villas, la prebostad va a sufrir un notorio revisionismo tras la llegada de los Reyes Católicos. Remitida a los tribunales la resolución de determinados aspectos o competencias, la inestabilidad gubernativa derivada conllevó en no pocos casos la intervención de la Corona mediante oportunos embargos, pesquisas y la cesión temporal del cargo en secrestaçión. En un contexto donde se suceden contundentes iniciativas tendentes a la desvinculación de los bandos en el seno de los concejos, con la implantación de ordenanzas modelo para la elección de los cargos municipales -Vitoria (1476), Bilbao (1483) ${ }^{63}$-, la figura del preboste es también parte constituyente y destacada de este proceso. Extender o igualar al cargo las atribuciones de los merinos mediante la adopción de un único arancel (Guipúzcoa 1492) ${ }^{64}$, o decretos como el embargo y reintegración general de las prebostades en el patrimonio real $(1502)^{65}$ con objeto de asentar definitivamente la potestad regia sobre los nombramientos, son actuaciones que deben enmarcarse necesariamente en esta compleja y polifacética dinámica. En ocasiones, las probanzas y alegaciones de

publicadas de su archivo. Con todo, para una visión de conjunto sobre el regimiento, nómina y titulares de los cargos municipales remitimos al siguiente trabajo de próxima aparición: VITORES CASAdo, Imanol. «Ser más poderoso y tener más parte en la Corte. Redes políticas y clientelares en el Bilbao bajomedieval» (en prensa).

63 Para una visión de conjunto García Fernández, Ernesto. Gobernar la ciudad en la Edad Media: oligarquias y élites urbanas en el País Vasco. Vitoria-Gasteiz: Diputación Foral de Álava, 2004, pp. 211-278.

64 AGS, RGS, legs, 1494-II, fol. 178; 1495-V, fol. 311.

65 González, Tomás. Colección de cédulas, cartas-patentes, provisiones, reales órdenes y otros documentos concernientes a las provincias vascongadas. Madrid: En la Imprenta Real, 1829, vol. 1, núm. XCIII, pp. 317-321. 
los titulares, volcados en salvaguardar las atribuciones del cargo, consiguen retratar con precisión el poder y la posición detentadas por el preboste en el marco de las villas:

«Martin d'Engonez, preboste de la dicha villa [de San Sebastian] nos fizo relaçion dizendo [...] tener voz [...] con el conçejo de la dicha villa, como preboste d'ella, e que es la segunda boz luego despues de los alcaldes. E ansymesmo diz que han estado y él está en la dicha posesion [...] de entender como preboste en las derramas e repartimientos que en la dicha villa y en su tyerra se han acostunbrado y se acostunbran fazer, y ver conplir fazer y votar en ello. Y en la presentaçion de los venefiçios e epystolanias que en la dicha villa e en los beneficios d'ella se fazen, y en llevar como preboste una de las varas del panno que se llevan sobre'l corpus Xhripsti el dia que se soleniza la fystevydad del corpus Xhripsti, y en las otras proçesyones que en la dicha villa se acostunbran fazer. E de yntitular el dicho preboste en las cartas e contratos e ynstrumentos que en la dicha villa y por el conçejo d'ella se acostumbran dar y otorgar, y en todos los otros abtos que por conçejo se fazen [...]. Asymesmo los dichos prebostes sus anteçesores e él, diz que an estando y estan sucesivamente en posesyon paçifica [...] de ser esentos de todos los tributos e derramas e repartimientos qu'en esta dicha villa se an fecho e fazen e acostunbran fazer, e de no contribuyr en ello por persona ni por fazyenda nin en otra manera alguna $[\ldots]{ }^{66}$.

\section{LA PREBOSTAD COMO RENTA DE NATURALEZA ADUANERA}

En el ámbito de la fiscalidad, al reparar tanto en la terminología como en los tipos impositivos de la prebostad, una necesaria reflexión previa se impone, encaminada en este caso a comparar y situar dicha renta en el marco de conjunto sobre el que actúa. Inexistente bajo dicha acepción en otros territorios de la Corona de Castilla, el término traslada nuestra atención al sistema impositivo del litoral gascón. Operante en La Rochelle en tiempos de Leonor de Aquitania ${ }^{67}$, la extensión de los modelos forales -0 cartas de la comuna- de esta junto con los de Rouen y Falaise sancionaría el establecimiento de la prebostat como tributo regio en las posesiones inglesas del continen$\mathrm{te}^{68}$. De forma paralela, la conformación de cordones aduaneros y tributos específicos sobre las actividades marítimas parecen sucederse tanto aquí como en los territorios de la Cornisa Cantábrica. Mediante fórmulas distintas, monarcas como Ricardo I o Alfonso VIII detraen ingresos sobre prácticas como la caza de la ballena ${ }^{69}$, al tiempo

66 AGS, RGS, leg. 1489-VII, fol. 255.

67 Favreau, Robert. "Les debuts de la ville de La Rochelle». Cahiers de Civilisation Médiévale, 1987, vol. 30, n. ${ }^{\circ} 117$, p. 10.

68 Balasque, Études historiques, vol. I, p. 364. En la cercana Bayona a fines del siglo xv el «peaje de la prebostad» era puesto en arrendamiento. Archives municipales de Bayonne. Livre des Établissements. Bayonne: Impr. Lamaignère, 1892, p. XLI.

69 En Biarritz, el monarca inglés había procedido ya a sustituir este derecho por un impuesto ordinario en moneda debido por todo el vecindario. BALASQUE, Études historiques, vol. I, pp. 450-451. Por su parte, Alfonso VIII haría donación a la orden de Santiago de la primera ballena que anualmente debían los pescadores de Motrico, siendo posteriormente reproducido este derecho en localidades como Guetaria, Zaráuz y San Sebastián. Ciriquiain Gaiztarro, Mariano. Los vascos en la pesca de la ballena. 
que comprobamos la aparición de impuestos como el de los diezmos en los puertos ${ }^{70}$. En Castilla, durante la primera mitad del siglo XIII el tipo impositivo de este gravamen aduanero, que acabará tomando carácter general y ordinario, pareció modificarse, pasando de un «treinteno» al diezmo ${ }^{71}$. En el colindante señorío de Vizcaya, cartas puebla como la de Portugalete (1322), que contaban con términos de la mar para matar ballenas, incluían conceptos como el quincio sobre la pesca o el treintazgo sobre la carga y descarga de mercancías entre los derechos debidos a los titulares del territorio ${ }^{72}$, quedando integradas después, como vimos, en la prebostad.

La implantación de la renta diezmos de la mar, cuyos parámetros comienzan a ser mejor conocidos a partir de las cuentas de Sancho IV, no conllevó la sustitución o desaparición de la prebostad, perviviendo, por tanto, en el tiempo como impuestos diferenciados. Correspondientes a la decimocuarta centuria, puntuales referencias constatan la operatividad de esta tanto en villas litorales como de interior. En San Sebastián (1351), la sucesión del cargo entre los miembros de los Mans-Engómez, requirió el envío previo de recaudos çiertos. Pedro I sancionaría el nuevo nombramiento a favor de Martín Gómez, haciendo referencia expresa a las rentas e pechos que al dicho ofiçio pertenecen junto a la media ballena de Guetaria y a determinados derechos a cobrar anualmente sobre Fuenterrabía ${ }^{73}$. Hacía poco más de una década Alfonso XI había eximido al concejo de Mondragón de toda «resura» y «mienda», tributos que el prestamero de la tierra pretendía exigir sobre las cosas que conpravan fuera de la dicha villa [...] e las trayan en bestias alquiladas como pertenecientes a la prebostad ${ }^{74}$. Llegado el siglo Xv, el arancel de Deva establecía en base a las gavias o velas de la embarcación en cuestión los tipos a recaudar, haciéndolo solo sobre el género en propiedad de extranjeros, incluyendo al transportado en navíos locales. Gravando exclusivamente la importación, sobre productos de abastecimiento como el trigo, la cebada y la sal recaen

\footnotetext{
San Sebastián: Ediciones Vascas, 1961, pp. 39-66. Tiempo después, las Cortes de Jerez de 1268 concedían competencias a determinados oficiales para el control del movimiento de mercancías en las localidades portuarias del reino. Como agentes o delegados exclusivos para la toma de fianzas a los mercaderes, en las villas de San Sebastián y Fuenterrabía, este cometido era encargado a una pareja de delegados entre los que constaban los respectivos prebostes. «Los omnes que han a tomar los fiadores en los puertos sobre dichos son estos: [...] En Sant Sebastian Guillen Peres de Ma[ns], el prioste Martin Garcia de Arana. En Fuenterrabia Garci Johan e el preboste». Cortes de los antiguos reinos de León y de Castilla. Madrid: Real Academia de la Historia, 1861, T. I, p. 74 (artículo 22).

70 Vid. notas 13-14.

71 Confirmaciones de la merced otorgada por Alfonso VIII sobre los diezmos de los puertos de las Cuatro villas cántabras a favor del obispo y cabildo de Burgos se refieren al asunto en los siguientes términos: «que despues que los reyes onde nos venimos ovieron los diezmos de los puertos en lugar del treynteno que los reyes solian aver». AGS, PTR, leg. 58, fol. 103.

72 Iturriza y Zabala, Historia General, vol. II, escritura n. ${ }^{\circ} 56$.

73 En 1416, el traspaso de la prebostad en Amado Martínez se retrasó al menos tres meses por cuanto el concejo había procedido a recaudar esta en fieldad, aprovechando la vacante, sin reconocer el nuevo nombramiento. Banús y Aguirre, «Prebostes de San Sebastián», pp. 27-28 y 47-48.

74 Herrero Liceaga, Victoriano José y otros. Archivo municipal de Mondragón. Tomo V. Libro 2. Copia de privilegios antiguos (1217-1520). San Sebastián: Eusko Ikaskuntza, 1998, doc. 13.
} 
tasas en especie ${ }^{75}$. Artículos específicos se refieren a los géneros procedentes de Vizcaya y de otros señoríos, estableciendo las mismas cuotas que las debidas por los foráneos al reino, si bien precisando la costumbre de «llevar un plato» sobre otras especies comestibles $^{7}$. En Fuenterrabía, las averiguaciones realizadas por los comisionados de Castilla y Francia en torno a la propiedad del Bidasoa (1509) hacían de la fiscalidad un elemento definitorio, señalando los conceptos de "diezmo viejo», "prebostazgo», «anclaje», «sisa» $\mathrm{y}$ «lonja» como los únicos operantes en el canal ${ }^{77}$.

En Vizcaya, el arrendamiento general de las rentas del Seńorío (1416) revela los valores y titulares de 11 de las 19 prebostades existentes en el territorio ${ }^{78}$. Incluyendo la tercera parte de los diezmos de las parroquias correspondientes, dicho ańo el rédito se cifró en un total de 253.650 maravedís (84.550 reales de plata), situándola como una de las rentas más importantes de la tesoreríi ${ }^{79}$. A tenor de lo contemplado en las cifras, la ría del Nervión constituye sin lugar a duda el principal punto de actividad económica del señorío, correspondiendo en exclusividad a los prebostes de Bilbao y Portugalete el control y fiscalización del tráfico de personas y mercancías. Desde mediados del siglo xv, los respectivos titulares y concejos inician una prolongada actividad en los tribunales con objeto de dirimir el ámbito de actuación sobre la carga y descarga de mercancías que se producían en la misma. Debido al bajo cauce de las aguas, las embarcaciones de alto tonelaje debían detenerse en el término de Bostintxaurreta para, mediante transbordo, suplir la distancia que mediaba con Bilbao en naves más ligeras. Sirviéndose de la coyuntura, equiparando dicha práctica a la entrada y salida de géneros sobre tierra, los prebostes de Portugalete impusieron el pago de las oportunas tasas, reblando así la tributación del comercio bilbaíno. Instituciones como la Hermandad de Vizcaya o la cofradía y consulado de mercaderes de Burgos, como partes agraviadas, tomarán también parte activa en la resolución de un dilatado conflicto del que, finalmente, sabrá beneficiarse la Corona. Frente al mero control sobre los nombramientos de las prebostades vizcaínas ${ }^{80}$, en el

75 "Que aya de llevar e lleve de qualquier navio que toviere gavias tres fanegas de qualquier çebera e sal que troxiren, e de otro qualquier navio syn gavias de qualquier portante que atravesare la mar dé dos fanegas de la dicha çebera e sal de franceses e ingleses e de otro qualquier estrangero, tanto que non sea de los reynos de Castilla realengos». AGS, RGS, leg. 1490-VIII, fol. 186; leg. 1491-III, fol. 117.

76 "Yten quando quiera que del condado de Viscaya e de otro qualquier condado e sennorio venieren sardina fresca o fruta de comer, que en tal caso que enbie el dicho preboste un plato e lleve segund ha usado e acostumbrado, e sy los mercaderes e navios del dicho condado truxieren trigo e çenteno o otra çevera a esta dicha villa para lo vender que paguen el prebostadgo asy como pagan los bretones e ingleses e françeses». Ibídem.

77 AGS, PTR, leg. 14-2, fol. XXXv.

78 Fruto de las irregularidades en la gestión de la tesorería, fundamentalmente en lo relativo al pago de tierras, acostamientos y mercedes, las protestas elevadas por vasallos y beneficiarios dieron pie al decreto por orden de la reina Catalina. Tras la conveniente pesquisa, la medida pretendía implantar el régimen de arrendamiento sobre todas las rentas de la tesorería de Vizcaya. Subsanados algunos puntos, las formas de recaudación seguirían siendo, no obstante, las anteriormente empleadas. Una disertación más detallada al respecto en Vitores Casado, Poder, sociedad y fiscalidad, pp. 80-81.

79 Ibidem, p. 382.

80 Nóminas de titulares en funciones constan en los libros de la tesorería como puede comprobarse en AGS, CMC-1 ${ }^{\text {a }}$, leg. 137. 
caso de Bilbao, a partir de la segunda mitad del siglo xvi dicha renta quedará integrada en el régimen general de arrendamientos de la Real Hacienda para su periódica salida en almoneda ${ }^{81}$.

Por otro lado, el arancel de la villa de Bermeo tasaba de forma prolija tanto la importación como la exportación de una amplia gama de mercancías. Generalmente fijadas en moneda de cuenta, los artículos referentes al hierro y acero siguen tomando como referencia los antiguos «dineros viejos», mientras que los productos de abastecimiento -pescado, trigo, centeno, vinos, frutas, ceras- asientan sus cuotas en porcentajes, bajo la premisa de treynta $u n o^{82}$. El articulado, que insiste en señalar la jurisdicción exclusiva de los prebostes en lo referente a la recaudación, incluye igualmente amplios poderes de intervención para el control del contrabando, quedando a merced de estos la emisión de los pertinentes permisos para la salida de navíos y medios de transporte terrestres. Referencias expresas a portazgos y pontazgos son incluidas también en este sentido, con objeto de enfatizar la pertenencia o integración de ambas figuras impositivas en la prebostad ${ }^{83}$. Amparándose en antiguos privilegios de exención a este respecto, concejos foráneos al señorío, en representación de los mercaderes que acudían a las plazas vizcaínas, tratan de obtener convenientes sentencias con la finalidad de extender estos al "treintazgo". En Bilbao, bajo la titularidad de los Leguizamon, localidades como Zumaya ${ }^{84}$, Motri$\mathrm{co}^{85}$, San Sebastián ${ }^{86}$ o Vitoria ${ }^{87}$ inician sendos procedimientos obteniendo en ocasiones resoluciones favorables en este sentido. Por las mismas fechas, los prebostes de Bermeo y Lequeitio se ven en la tesitura de hacer valer sus derechos al respecto en sendos pro$\operatorname{cesos}^{88}$. Con todo, los testimonios y probanzas aducidos por los oficiales insistían en subrayar el carácter regio de la prebostad, así como su distinción frente al portazgo y, por consiguiente, la obligatoriedad del pago al igual que ocurría con otras rentas aduaneras exigidas en distintos territorios de la Corona:

«Ca çierto es, los de la çibdad de Bitoria non han nin tienen privillegio contra el dicho preboste para no pagar el dicho trentadgo, e si algund previllegio tienen es de portadgos, que es otro derecho distinto e apartado de treintadgo, ca en el condado e sennorio de Vizcaya, do es la dicha villa de Bilvao, en la qual es preboste el dicho mi parte, ay tres maneras de derecho e non más, es a saber: de portadgo, dezmeria e treintazgo, e todos ellos son diferentes el

81 Desde mediados del siglo Xv, lo tocante a los conflictos y procesos judiciales entre los titulares de ambas prebostades lo analizamos de forma exhaustiva en Vitores CASAdo, Poder, sociedad y fiscalidad, pp. 388-395. Las cifras en torno a los primeros arrendamientos de la prebostad bilbaína pueden consultarse en AGS, Expedientes de Hacienda, leg. 60.

82 En la vecina Lequeitio las denominaciones empleadas para el caso se refieren al treintadgo, o tres por çiento. ARChV, Sala Vizcaya, leg. 2014-1.

83 La edición del arancel de Bermeo la publicamos en su momento en Goicolea Julián, Francisco Javier y García Fernández, Ernesto. Las Haciendas medievales en el País Vasco y La Rioja. Textos para su estudio. Madrid: Instituto de Estudios Fiscales, 2012, doc. 58.

${ }_{84}$ Elorza Maiztegi, Archivo Municipal de Zumaia, docs. 58 y 65.

85 ARChV, Sala Vizcaya, leg. 1995-4.

86 ARChV, Reales Ejecutorias, 297-23.

87 ARChV, Sala Vizcaya, leg. 2997-6, Reales Ejecutorias, 261-11.

88 ARChV, Reales Ejecutorias, 271-83; 323-27. 
uno del otro, e el que es libre de portadgo no es libre de treintazgo. E lo otro porque los de la dicha çibdad de Bitoria por tienpo inmemorial siempre han pagado a los prebostes de la dicha villa el dicho treintazgo [...]. E ansý ay en muchas partes d'estos regnos, espeçialmente en la çibdad de Sevilla, e en otros muchos lugares de puertos ay portazgo e almoxarifazgo e otros muchos derechos, los quales se pagan por diversos derechos, e sy todo fuese uno no tenría diversos nonbres nin se pagarían más de un derecho» ${ }^{89}$.

\section{A MODO DE BALANCE O CONCLUSIÓN}

La aparición de la figura de la prebostad, resultado del proceso de creación de las villas, es un elemento integrante del sistema gubernativo implantado por la monarquía en los nuevos y privilegiados enclaves. Pese a la diversidad de ordenamientos o fueros de francos extendidos en los territorios vascos, la incorporación de dicho cargo impuso características comunes en los cuadros administrativos y financieros de los concejos. Una pretendida asimilación se intuye no obstante en el diseño y finalidad de los modelos implantados a este respecto por parte de los monarcas y señores del periodo. La concreción de cordones aduaneros es un fenómeno paralelo al desarrollo de la administración local. Debido a ello, actuaciones similares se suceden en lo relativo a la organización territorial de los reinos y señoríos asentados en el Golfo de Vizcaya. La prebostad, y su marcada implantación en buena parte de las localidades de dicho margo geográfico, es sin duda fiel reflejo de esta casuística.

Encarnando el poder ejecutivo del monarca o del señor en suelo urbano, las atribuciones ańadidas en materia tributaria hacen del preboste una magistratura sinónimo de autoridad y encumbramiento. De forma temprana, la restricción de acceso es perseguida por las élites, sancionando en adelante su cesión en merced una vez que escogidos linajes y parentelas han conseguido asentarse en su ejercicio. La antigua anualidad deja paso a una titularidad vitalicia que, sin duda, ayudó a trastocar el equilibrio de fuerzas que regía o amparaba las relaciones internas de los concejos. Frente a la alternancia de alcaldes, fieles y regidores, el preboste ejerce una presencia continuada, participando e influyendo en la toma de decisiones de la corporación municipal. Ello explica en parte la relevancia del papel jugado por sus titulares en la dirección de bandos locales o su participación en las grandes parcialidades de Ońez y Gamboa. A fines del siglo xv, la intervención de los concejos y el revisionismo de las competencias del cargo se debe también a la progresiva pérdida de influencia de esta antigua élite estrechamente vinculada al servicio militar.

En el terreno de la fiscalidad, la cesión íntegra de las competencias y réditos de la renta sancionó su práctica enajenación. Desgajada del régimen general de arrendamientos, la recaudación y gestión de los distintos conceptos aduaneros que conformaban la prebostad queda bajo la autoridad del titular en funciones. El control de tesoreros, contadores mayores u otros órganos de la Real Hacienda a este respecto pareció limitarse al mero registro de las renuncias y traspasos habidos en el cargo.

89 ARChV, Reales Ejecutorias, 261-11. 
Consecuencia de ello, y ante la manifiesta carencia de registros contables, delimitar la naturaleza e importancia de esta renta aduanera hace obligado el recurso a las fuentes indirectas, fundamentalmente a las de naturaleza judicial. Con todo, si reparamos en las informaciones de orden cualitativo derivadas, cabría subrayar la importancia de la prebostad como primigenio cordón aduanero en los territorios vascos septentrionales; paralelo o superpuesto al delimitado por otras rentas regias como diezmos y portazgos. Pese a sus aparentes especificidades a nivel local -en lo relativo a las tasas o bases imponibles-, esta llegó a jugar un representativo papel para la promoción económica de los titulares en el cargo, amén de una notoria potestad para el control del tráfico de personas y mercancías. A fines de la Edad Media, la actuación de determinados concejos o de la propia monarquía para su reintegración en el patrimonio público vendrían a constatar la trascendencia de unos réditos y de una figura sobre la que la historiografía precedente apenas había reparado.

\section{ApÉNDice de TABLAS}

TABLA 1. Tipología de las mercedes para el nombramiento de prebostes*

\begin{tabular}{|l|l|l|l|l|l|}
\hline \multirow{2}{*}{ Fecha } & \multirow{2}{*}{ Villa } & \multirow{2}{*}{ Beneficiario } & \multicolumn{2}{l}{ Merced } & \multirow{2}{*}{ Quitaciones y atribuciones seńaladas } \\
\cline { 4 - 5 } & & Con. & Tipo & \\
\hline 1285 & San Sebastián & Guillem Per de Mans & H. & J. H. & Derechos y media ballena Guetaria \\
\hline 1451 & Mondragón & Lope García de Arcaraso & N. V. & V. & Derechos, quitaciones, franquezas \\
\hline 1475 & San Vicente de la Barquera & García de Oreńa & H. & V. & Derechos, salarios, franquezas \\
\hline 1475 & Ondárroa & Martín Ruiz de Arancibia & H. & T./V. & Derechos, peaje, franquezas \\
\hline 1476 & Portugalete & Pedro de Salazar & H. & T./J. H & Derechos, salarios, peajes, franquezas \\
\hline 1485 & Cestona & Juan Beltrán de Iraeta & H. & V. & Patronazgos, derechos, quitaciones y exenciones \\
\hline 1485 & Durango & Francisco de Arteita & N. V. & V. & Derechos, salarios, quitaciones, inmunidades \\
\hline 1486 & Villaviciosa Marquina & Furtún Ibáńez de Marquina & H. & T./V. & $\begin{array}{l}\text { Merindad, patronazgo, derechos, salarios, } \\
\text { franquezas, inmunidades }\end{array}$ \\
\hline 1488 & Bilbao & Tristán de Leguizamón & N. V. & V. & $\begin{array}{l}\text { Derechos, quitaciones, salarios, franquezas, } \\
\text { inmunidades }\end{array}$ \\
\hline 1495 & Motrico & Martín Ibáńez de la Plaza & H. & V. & Derechos, salarios, franquezas, inmunidades \\
\hline 1496 & Fuenterrabía & Concejo & N. & P. & $\begin{array}{l}\text { 2/3 renta concejo, 1/3 titular nombrado por } \\
\text { concejo }\end{array}$ \\
\hline 1497 & Bermeo & Flores de Arteaga & H. & T./V. & Derechos, salarios, treintazgos \\
\hline 1498 & Orio & Nicolás de Guevara & N. V. & V. & Derechos, salarios, honras, preeminencias \\
\hline 1503 & Bermeo & Juan de Arteaga & H. & T./V. & Derechos, salarios, treintazgos \\
\hline
\end{tabular}

* Selección de registros que en ningún caso se refiere al total de las concedidas o conservadas.

Con.: concesión; H.: heredada; N. V.: nueva por vacante; J. H.: juro de heredad; T./V.: tierra vitalicia; P.: perpetua. Fuente: AGS, RGS, legs. 1475-III, fol. 257; 1475-VIII, fol. 577; 1476-III, fol. 112; 1495-XI, fol. 10; 1498-II, fol. 258. AGS, EMR, TCV, leg. 1, fols. 23 y 30; leg. 2, fols. 104 y 254. AGS, EMR, MP, leg. 70, fol. 54. Ayerbe Iribar y Elorza Maiztegi, Archivo Municipal de Zestoa, doc. 37. Banús y Aguirre, «Prebostes de San Sebastián», p. 17. Crespo Rico y otros. Colección documental del Archivo Municipal de Mondragón, doc. 127. Larrañaga Zulueta y Tapia Rubio, Colección documental del Archivo Municipal de Hondarribia, vol. III, doc. 6. 
TABLA 2. Valor de las prebostades según el arrendamiento general de las rentas de la tesorería de Vizcaya de 1416

\begin{tabular}{|c|c|c|c|}
\hline Prebostad & Mrs. & Reales & Titular* \\
\hline Elorrio & 150 & 50 & Rodrigo de Unda \\
\hline $\begin{array}{l}\text { Ermua [prebostad ( } 200 \mathrm{mrs}) \text { y tercias de la iglesia de Santiago de Ermua } \\
(4.500 \mathrm{mrs})]\end{array}$ & 4.700 & $1.566,7$ & $\begin{array}{l}\text { Fernán Pérez de Zaldívar / } \\
\text { Fernando de Zaldívar } \\
\end{array}$ \\
\hline Villaro [prebostad (1.200) y tercias de San Bartolomé de Villaro (1.000)] & 2.200 & 733,3 & $\begin{array}{l}\text { Íñigo Martínez de Zuazti / } \\
\text { Pedro de Abendańo }\end{array}$ \\
\hline Guernica & 2.600 & 866,7 & Juan de Meceta \\
\hline Bermeo & 6.000 & 2.000 & Furtún García de Arteaga \\
\hline Bilbao [prebostad (140.000) y tercias de Sta. M. a de Begońa (2.000)] & 142.000 & $47.333,3$ & Furtún Sánchez de Bedia \\
\hline 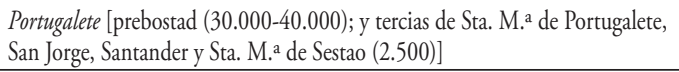 & 42.500 & $14.166,7$ & Ochoa de Salazar \\
\hline Lequeitio: [prebostad (25.000) y tercias de Sta. M. a de Lequeitio (16.000)] & 41.000 & $13.666,7$ & $\begin{array}{l}\text { Rodrigo Adán de Yarza / } \\
\text { Francisco Adán de Yarza }\end{array}$ \\
\hline Plencia & 5.500 & $1.833,3$ & $\begin{array}{l}\text { Concejo (arrendamiento sin } \\
\text { tercias y sin derechos del monte }\end{array}$ \\
\hline Ondárroa [prebostad (?) y tercias de Sta. M. ${ }^{\text {a de Ondárroa] }}$ & 5.000 & $1.666,7$ & Martín Ruiz de Arancibia \\
\hline Guerricáiz [prebostad (?) y tercias de Sta. M. a de Guerricáiz] & 1.000 & 333,3 & Rodrigo Martínez de Gareca \\
\hline Durango [prebostad (?) y tercias de Sta. M. ${ }^{a}$ de Durango] & 1.000 & 333,3 & Francisco Adán de Yarza \\
\hline
\end{tabular}

* En determinadas ocasiones la titularidad de las prebostades seńalada en el documento no es coincidente, por lo que incluimos todas las referencias halladas.

Fuente: Enríquez Fernández y otros, Colección documental del Archivo Municipal de Lequeitio, doc. 52.

TABLA 3. Valor de los arrendamientos de la prebostad de Bilbao durante los siglos XV-XVI

\begin{tabular}{|c|c|c|}
\hline Fecha & Maravedís & Reales \\
\hline 1416 & 142.000 & $47.333,3$ \\
\hline $1522^{*}$ & 375.000 & $11.029,4$ \\
\hline 1577 & 516.250 & $15.183,8$ \\
\hline 1582 & 829.000 & $24.382,4$ \\
\hline
\end{tabular}

*Estimación procedente de proceso judicial

Fuente: AGS, Expedientes de Hacienda, leg. 60; ARChV, Reales Ejecutorias, 361-24; EnríQuez FernáNDEZ y otros. Colección documental del Archivo Municipal de Lequeitio, doc. 52.

\section{REFERENCIAS BIBLIOGRÁFICAS}

Achón Insausti, José Ángel. 'A voz de Concejo'. Linaje y corporación urbana en la constitución de la Provincia de Gipuzkoa. San Sebastián: Diputación Foral de Gipuzkoa, 1995.

Archives municipales de Bayonne. Livre des Établissements. Bayonne: Impr. Lamaignère, 1892.

Ayerbe Iribar, M. ${ }^{a}$ Rosa y Elorza Maiztegi, Javier. Archivo Municipal de Zestoa (1338-1520).

San Sebastián: Eusko Ikaskuntza, 2008.

Balasque, Jules. Études historiques sur la ville de Bayonne. Bayonne: Lasserre, 1862, vol. I. 
LA PREBOSTAD DE LAS VILLAS VASCAS: ORIGEN Y TRANSFORMACIONES (SIGLOS XII-XVI)

IMANOL VITORES CASADO

Banús y Aguirre, José Luis. «Prebostes de San Sebastián. Los Mans y Engómez». Boletín de Estudios Históricos sobre San Sebastián, 1971, vol. 5, pp. 13-70.

Barrena Osoro, Elena. Ordenanzas de la Hermandad de Guipúzcoa (1375-1463). San Sebastián: Eusko Ikaskuntza, 1982.

Benavides, Antonio. Memorias de D. Fernando IV de Castilla. 2 vols. Madrid: Imp. de José Rodríguez, 1860.

Cañas Gálvez, Francisco de. El itinerario de la Corte de Juan II de Castilla (1418-1454). Madrid: Sílex, 2007.

Ciriquiain Gaiztarro, Mariano. Los vascos en la pesca de la ballena. San Sebastián: Ediciones Vascas, 1961.

Cortes de los antiguos reinos de León y de Castilla. Madrid: Real Academia de la Historia, 1861.

Crespo Rico, Miguel Ángel y otros. Colección documental del Archivo Municipal de Rentería. Tomo I (1237-1470). San Sebastián: Eusko Ikaskuntza, 1991.

Crespo Rico, Miguel Ángel y otros. Colección documental del Archivo Municipal de Mondragón. Tomo III (1451-1470). San Sebastián: Eusko Ikaskuntza, 1996.

Crónica de Alfonso VIII. Edición digital Paris: SEMH-Sorbonne - CLEA (EA 4083) (Les Livres d'e-Spania "Sources», 1), 2010, http://e-spanialivres.revues.org/187

Dacosta, Arsenio. Los linajes de Bizkaia en la Baja Edad Media: poder, parentesco y conflicto. Bilbao: Universidad del País Vasco, 2003.

Díez de SAlaZAR, Luis Miguel. El diezmo viejo y seco, o diezmo de la mar de Castilla (siglos XIII-XVI): aportación al estudio de la fiscalidad guipuzcoana. San Sebastián: Caja de Ahorros Municipal de San Sebastián, 1983.

Elorza Maiztegi, Javier. Documentación del Archivo Municipal de Zumaia (1256-1520). San Sebastián: Eusko Ikaskuntza, 2009.

Enríquez Fernández, Javier. Colección documental de los Archivos Municipales de Guerricáiz, Larrabezúa, Miravalles, Ochandiano, Ondárroa y Villaro. San Sebastián: Eusko Ikaskuntza, 1991.

Enríquez Fernández, Javier y otros. Colección documental del Archivo Histórico de Bilbao (13001473). San Sebastián: Eusko Ikaskuntza, 1999.

Favreau, Robert. «Les debuts de la ville de La Rochelle». Cahiers de Civilisation Médiévale, 1987, vol. 30, n. ${ }^{\circ} 117$, pp. 3-32.

Gaibrois de Ballesteros, Mercedes. Historia del reinado de Sancho IV de Castilla. Madrid: Real Academia de la Historia, 1922, vol. I.

García de Castro, Francisco Javier. La marina de guerra de la Corona de Castilla en la Baja Edad Media. Desde sus orígenes hasta el reinado de Enrique IV. Valladolid: Universidad de Valladolid, 2011 (Tesis doctoral inédita).

García de Cortázar, José Ángel. Vizcaya en el siglo XV. Aspectos económicos y sociales. Bilbao: Ediciones de la Caja de Ahorros Vizcaína, 1966.

García de Cortázar, José Ángel y otros. Bizcaya en la Edad Media. San Sebastián: Haranburu Editor, 1985, vol. IV.

García Fernández, Ernesto. Gobernar la ciudad en la Edad Media: oligarquias y élites urbanas en el País Vasco. Vitoria-Gasteiz: Diputación Foral de Álava, 2004.

Goicolea Julián, Francisco Javier y García Fernández, Ernesto. Las Haciendas medievales en el País Vasco y La Rioja. Textos para su estudio. Madrid: Instituto de Estudios Fiscales, 2012.

González, Julio. El reino de Castilla en la época de Alfonso VIII. 3 vols. Madrid: Escuela de Estudios Medievales, 1960.

González, Tomás. Colección de cédulas, cartas-patentes, provisiones, reales órdenes y otros documentos concernientes a las provincias vascongadas. 4 vols. Madrid: En la Imprenta Real, 1829-1830. 


\section{2}

González Mínguez, César. Documentos de Pedro I y Enrique II en el Archivo Municipal de Vitoria. San Sebastián: Eusko Ikaskuntza, 1994.

Gorosábel, Pablo de. Diccionario histórico-geográfico-descriptivo de los pueblos, valles, partidos, alcaldías y uniones de Guipuzzcoa con un apéndice de las cartas puebla y otros documentos importantes. (1. ${ }^{\mathrm{a}}$ ed. Tolosa, 1862). Bilbao: La Gran Enciclopedia Vasca, 1972.

Herrero Liceaga, Victoriano José y Barrena Osoro, Elena. Archivo Municipal de Deba. I. (1181-1520). San Sebastián: Eusko Ikaskuntza, 2005.

Herrero Liceaga, Victoriano José y otros. Archivo municipal de Mondragón. Tomo V. Libro 2. Copia de privilegios antiguos (1217-1520). San Sebastián: Eusko Ikaskuntza, 1998.

Hidalgo de Cisneros, Concepción y otros. Fuentes jurídicas medievales del Señorío de Vizcaya. Cuadernos legales, Capitulos de la Hermandad y Fuero Viejo (1342-1506). San Sebastián: Eusko Ikaskuntza, 1986.

IrIJOA CoRTÉs, Iago. «Donostiako probestutzaren oinordetza XIII eta XIV. mendeetan: Ordincho Mans-ekoaren eta Martin Gomez-en garaietako korapiloak askatuz». Boletin de Estudios Históricos sobre San Sebastián, 2016, vol. 49, pp. 623-631.

IrIjOA Cortés, Iago. «Gobierno urbano en San Sebastián a fines de la Edad Media: crisis de linaje, conflictos y reestructuración política». Boletín de Estudios Históricos sobre San Sebastián, 2016, vol. 49, pp. 19-37.

IrIjOA Cortés, Iago. Estudio de la vida urbana guipuzcoana: los valles del Oria y Urumea en la Baja Edad Media. Vitoria-Gasteiz: Universidad del País Vasco, 2015 (Tesis doctoral inédita).

Iturriza y Zabala, Juan Ramón de. Historia general de Vizcaya y epitome de las Encartaciones. 2. ${ }^{a}$ ed. Bilbao: Ediciones de la Librería Arturo, 1983.

Lacarra de Miguel, José María. «Fuero de Estella». Anuario de Historia del Derecho Español, 1927, vol. 4, pp. 404-450.

Larrañaga Zulueta, Miguel y Tapia Rubio, Izaskun. Colección documental del Archivo Municipal de Hondarribia. Tomo I (1186-1479). San Sebastián: Eusko Ikaskuntza, 1993.

Las Siete Partidas. 3 vols. Madrid: Boletín Oficial del Estado, 2004.

Líbano ZumalacárRegi, Ángeles. «Consideraciones lingüísticas sobre algunos tributos medievales navarro-aragoneses y riojanos». Príncipe de Viana, 1979, vol. 40, n. ${ }^{\circ}$ 154-155, pp. 65-80.

Martín Duque, Ángel J. «El fuero de San Sebastián. Tradición manuscrita y edición crítica». En Congreso El Fuero de San Sebastián y su época. San Sebastián: Sociedad de Estudios Vascos, 1982, pp. 3-25.

Martínez Díez, Gonzalo. «Fueros locales en el territorio de la provincia de Santander». Anuario de Historia del Derecho Español, 1976, vol. 46, pp. 527-608.

Monlezun, Jean-Justin. Histoire de la Gascogne depuis les temps les plus reculés jusqu’à nos jours. Vol. II. Auch: J. A. Portes, Imprimeur, 1850.

Orella Unzué, José Luis. «La familia del fuero de Logroño en Guipuzkoa hasta la promulgación de la merindad mayor en el Ordenamiento de Alcalá en 1348». En García Turza, Francisco Javier y Martínez Navas, Isabel (coords.). Actas de la reunión cientifica El Fuero de Logroño y su época. Logroño: Ayuntamiento de Logroño, 1996, pp. 323-389.

Orella UnzuÉ, José Luis. «Régimen municipal en Guipúzcoa en los siglos XIII y XV». Lurralde: Investigación y espacio, 1979, vol. 2, pp. 103-267.

Pamplona, Germán de. «Sancho el Fuerte, iniciador de las relaciones amistosas con la ciudad de Bayona». Principe de Viana, 1962, vol. 23, n. ${ }^{\circ} 88-89$, pp. 495-500.

Ramírez Vaquero, Eloísa. «Hacienda y poder real en Navarra en la Baja Edad Media. Un esquema teórico". Príncipe de Viana, 1999, vol. 60, n. ${ }^{\circ}$ 216, pp. 87-118.

Romero ANDONEgi, Asier. «La figura del teniente de preboste o "prebostao" en las villas marítimas del señorío de Vizcaya». Zainak. Cuadernos de Antropología-Etnografía, 2002, vol. 21, pp. 317-332. 
Salazar Acha, Jaime de. "La cancillería real en la Corona de Castilla». En Sarasa SÁnchez, Esteban (coord.). Monarquía, crónicas, archivos y cancillerías en los reinos hispano-cristianos. Zaragoza: Institución Fernando el Católico, 2014, pp. 309-324.

SáncheZ-Arcilla Bernal, José. «La administración de justicia en León y Castilla durante los siglos X al XiII». En Riesco Terrero, Ángel (coord.). I Jornadas sobre documentación jurídicoadministrativa, económico-financiera y judicial del reino castellano-leonés (siglos X-XIII). Madrid: Universidad Complutense de Madrid, 2002, pp. 13-49.

Tena García, M. a Soledad. «Los Mans-Engómez: el linaje dirigente de la villa de San Sebastián durante la Edad Media». Hispania, 1993, vol. 185, pp. 987-1008.

Tena García, M. a Soledad. La sociedad urbana en la Guipúzcoa costera medieval: San Sebastián, Rentería y Fuenterrabia (1200-1500). San Sebastián: Instituto Doctor Camino, 1997.

Villacorta Macho, M. ${ }^{a}$ Consuelo (ed.). Bienandanzas e fortunas. Bilbao: Universidad del País Vasco, 2015.

Vitores Casado, Imanol. «Agentes económicos e instituciones públicas en la configuración del mercado del hierro vasco (siglos XIV-XVI): poder, crédito y finanzas». En la España Medieval, 2017, vol. 40, pp. 191-247.

Vitores Casado, Imanol. «Ser más poderoso y tener más parte en la Corte. Redes políticas y clientelares en el Bilbao bajomedieval» (en prensa).

Vitores Casado, Imanol. Poder, sociedad y fiscalidad en el Señorio de Vizcaya durante la Baja Edad Media. Vitoria-Gasteiz: Universidad del País Vasco, 2014 (Tesis doctoral inédita).

Zabala, M. ${ }^{a}$ José. «La creación de las villas en el Señorío de Bizkaia: los fueros y las cartas pueblas». Cuadernos de Sección Historia-Geografía Eusko Ikaskuntza, 1995, vol. 23, pp. 11-29. 